\title{
Validation of Sea Surface Wind From Sentinel-1A/B SAR Data in the Coastal Regions of the Korean Peninsula
}

\author{
Jang Jae-Cheol ${ }^{1}$, Park Kyung-Ae ${ }^{2}$, Mouche Alexis ${ }^{3}$, Chapron Bertrand ${ }^{3}$, Lee Ji-Hyun ${ }^{1}$
}

1 Seoul Natl Univ, Dept Sci Educ, Seoul 08826, South Korea.

2 Seoul Natl Univ, Res Inst Oceanog, Ctr Educ Res, Dept Earth Sci Educ, Seoul 08826, South Korea.

3 IFREMER, CERSAT, F-29280 Plouzane, France.

Email addresses : jaecheol00@snu.ac.kr ; kapark@snu.ac.kr ; Alexis.Mouche@ifremer.fr ; bchapron@ifremer.fr ; ih.lee@snu.ac.kr

\begin{abstract}
:
In this study, using in situ measurements at 17 buoy stations off the Korean Peninsula, C-band model (CMOD) functions for Sentinel-1A/B IW mode synthetic aperture radar (SAR) data were validated. In total, 395 Sentinel-1A/B IW mode dual-vertical polarized images were used for collocation with in situ measurements from May 1, 2015, to September 30, 2017, and 807 matchup points were obtained. Prior to the validation, preprocessing such as speckle noise reduction and ship and land masking was completed. The in situ wind speeds were converted to a $10-\mathrm{m}$ neutral wind considering atmospheric stability. High-resolution wind speeds were estimated by using the CMOD functions such as CMOD4, CMOD_IFR2, CMOD5, CMOD5.N, and CMOD5.Na. The root-mean-square errors of eachmodel were less than approximately $1.8 \mathrm{~m} . \mathrm{s}(-1)(1.83,1.82,1.69,1.68$, and $1.65 \mathrm{~m} . \mathrm{s}(-1)$, respectively). The biases of all models were higher in the western coastal region than those in the eastern coastal region. The results showed the advantages and disadvantages of each model in the estimation of wind speeds in the coastal region around the Korean Peninsula as proposed in a concept of combined errors. The wind speeds derived from the SAR data also presented a tendency for water depth to be overestimated over shallow bathymetry and to be underestimated at high wind speeds. In addition, this study assessed potential sources of wind speed errors such as the effects originating from wind direction input, different platforms of Sentinel-1A and Sentinel-1B and their calibration, and from radar interference or regional oceanic characteristic environments.
\end{abstract}

Keywords: C-band model (CMOD) functions, synthetic aperture radar (SAR), Sentinel-1A/B, wind speed, wind speed error 
$\mathbf{S}$ EA surface wind is extensively used to understand di-verse oceanic phenomena and the marine boundary layer. Because the wind field has long been affected by climate change and marine environmental changes and interest in climate change has increased, frequent observations of wind fields with reliable accuracy have been emphasized [1]

Since the early 1990s, many worldwide institutions, such as the European Space Agency (ESA), National Aeronautics and Space Administration (NASA), and Japan Aerospace Exploration Agency have developed the European Remote Sensing-1/2 (ERS-1/2), NASA Scatterometer, Quick Scatterometer, Advanced Scatterometer, and Rapid Scatterometer to contin-uously monitor sea surface wind fields in the global oceans with a relatively good spatial resolution of approximately $25 \mathrm{~km}$ [2]-[4]. The overall accuracy of the wind fields from the scat-terometers is approximately $2 \mathrm{~m} \cdot \mathrm{s}^{-1}$ for wind speed and $20^{\circ}$ for wind direction. Such data have been used to improve the accuracy of numerical forecast models and understand a va-riety of oceanic phenomena, including typhoons, eddies, and atmospheric-oceanic interactions [5][11]. Despite the avail-ability of scatterometers, their wind field data have limitations with a low spatial resolution of approximately $25 \mathrm{~km}$. The other limitations include no observations or limited data acquisition in coastal regions, which makes it difficult to study relatively small-scale oceanic phenomena and their response to the surface wind field [12], [13].

Synthetic aperture radar (SAR) is an active, all-weather, sensor. Numerous satellites with SAR have been launched and operated thus far, for example, ERS-1/2, shuttle imaging radar with payload C (SIR-C), RADARSAT-1/2, Envisat advanced synthetic aperture radar (ASAR), advanced land observing satellite phased array type L-band SAR (ALOS-1/2 PALSAR), TerraSAR-X, COnstellation of small Satellites for the Mediterranean Basin Observation (COSMO-SkyMed), and KOrean Multi-Purpose SATellite-5 (KOMPSAT-5). SAR has a higher spatial resolution than scatterometers such that it can produce much better wind field data with a high spatial resolution of less than $1 \mathrm{~km}$. This allows analyzing detailed wind fields with much higher spectral energy than those of the scatterometric winds [14]-[16]. Such SAR wind fields have been used for various applications, including coastal marine environmental monitoring [17]-[20], observation of marine environmental change related to cyclones [21], analysis of sea surface roughness change resulting from atmospheric gravity wave study [22]-[24], and sea surface wind study resulting from a change in stratification of the marine atmospheric boundary layer (MABL) [25], [26]. 


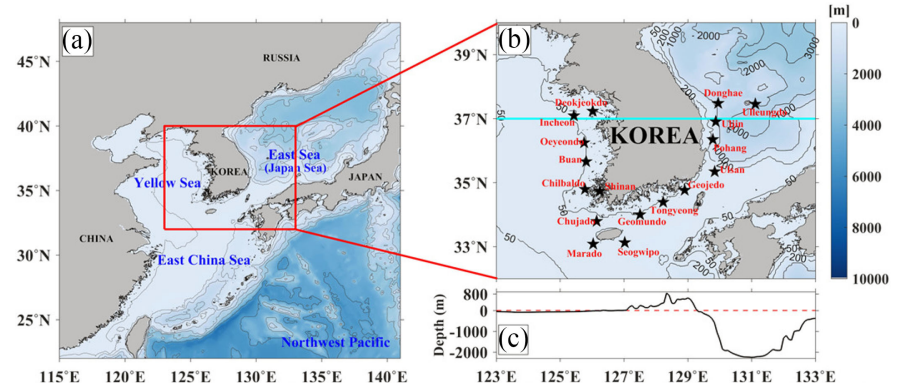

Fig. 1. (a) Location of the study area with contours of the water depth $(\mathrm{m})$ in the seas around the Northeast Asia including China, Japan, Korea, and Russia. (b) Large-scale bathymetry map of the coastal region around the Korean Peninsula, where the black stars and red text around the stars indicate the location and name of the KMA marine meteorological buoys, respectively. (c) Zonal section of topography along $37^{\circ} \mathrm{N}$ as shown in (b).

SAR wind speeds have been estimated using geophysical model functions (GMFs) developed from the backscattering coefficient of scatterometers. The GMFs, generally applied to single polarization SAR data, can be described as a relationship between the normalized radar cross section (NRCS), incidence angle, relative wind direction to the radar look angle, and wind speed. In the case of the C-band empirical GMFs, termed C-band models (CMODs), models such as CMOD4 [27], CMOD_IFR2 [28], CMOD5 [29], [30], CMOD5.N [31], and CMOD5.Na [32] have been commonly used for the estimation of wind speed from C-band SAR data. These CMOD functions, applied to SIR-C, ERS-1/2, RADARSAT-1/2, and Envisat ASAR, have successfully estimated wind fields with relatively good accuracy of less than $2.0 \mathrm{~m} \cdot \mathrm{s}^{-1}[33]-[37]$.

Sentinel-1A launched on April 3, 2014, and Sentinel-1B launched on April 22, 2016, with C-band SAR were developed for various applications, including global environmental monitoring, sea ice observation, emergency mapping, ship detection, oil spill mapping, and climate change monitoring [38]. Sentinel1A and Sentinel-1B orbit around the same orbit $180^{\circ}$ apart at an altitude of approximately $700 \mathrm{~km}$ with revisit time of about 12 days. Sentinel-1 IW mode has used Terrain Observation with Progressive Scans SAR (TOPSAR) operation in a way that the sensor electronically steers the beam in both range direction as ScanSAR operation and azimuth direction from backward to forward for each burst, so the observation data could avoid scalloping and achieve homogeneous image quality [39]. Using TOPSAR operation in Sentinel-1 IW mode, the data have a wide swath and a fine spatial resolution and thus is suitable for global environmental monitoring [40]. These characteristics enable construction of a database of Sentinel-1A/B data over a longer period than one year and assessment of the accuracy of wind speed in preparation for active use for diverse purposes [41].

The Korean Peninsula is located around the marginal seas in the northwest Pacific Ocean, surrounded by the Yellow Sea to the west, the East Sea/Japan Sea (EJS) to the east, and the East China Sea to the south [see Fig. 1(a)]. The bathymetry of the Yellow Sea is very shallow $(<44 \mathrm{~m})$ and strong tidal currents of a high tidal amplitude reaching up to $10 \mathrm{~m}$ occur west of the Korean Peninsula, but that of the EJS is comparatively deep with a maximum depth of more than $3000 \mathrm{~m}$. In total, 17 operational buoys produce measurements of most of the atmospheric and oceanic variables in the coastal region around the Korean Peninsula over several decades [see Fig. 1(b)], implying that this specific study area is suitable for the validation of Sentinel wind fields with in situ measurements because of the intensively distributed marine buoys. This coastal region is among the best sites to conduct the validation of wind speeds and understand the potential sources contributing to wind retrieval errors such as complex regional characteristics, including different water depth, numerous islands, and tidal currents.

Thus far, no studies have been completed to assess the accuracy of the sea surface wind from the Sentinel-1A/B SAR data using in situ measurements in the seas around the Korean Peninsula. The objectives of this study were to:

1) calculate the sea surface wind derived from Sentinel-1A/B using CMOD4, CMOD_IFR2, CMOD5, CMOD5.N, and CMOD5.Na;

2) produce a matchup database between the Sentinel-1A/B SAR data and in situ measurements in the seas around the Korean Peninsula;

3) estimate the accuracy of the sea surface wind from the Sentinel-1A/B SAR data by comparing it to the in situ measurements;

4) compare the wind speed results from all of the CMOD model types;

5) investigate the characteristics of the wind speed errors in this coastal region under diverse oceanic environmental conditions.

\section{DATA}

\section{A. In Situ Measurement}

To investigate the high-resolution sea surface wind from the Sentinel-1A/B data, we used the marine meteorological buoy data operated by the Korea Meteorological Administration (KMA). As presented in Table I, 17 KMA marine meteorological buoys are located in the seas around the Korean Peninsula as the buoy stations in the coastal areas of the Yellow Sea (Deokjeokdo, Incheon, Oeyeondo, Buan, Shinan, and Chilbaldo), in the southern region (Chujado, Marado, Seogwipo, Geomundo, Tongyeong, and Geojedo), and in the EJS (Ulsan, Pohang, Uljin, Donghae, and Ulleungdo). The symbols of the buoys are given provided to and following the first alphabet of the names of the seas, as from Y1 to Y6 for the Yellow Sea, from S1 to S6 for the southern coastal region, and from E1 to E5 for the EJS, respectively (see Table I). The KMA marine meteorological buoys observe air temperature, humidity, pressure, wind speed, wind direction, and sea temperature every hour and the meteorological parameters are observed at different elevations from 0.1 to $4.4 \mathrm{~m}$ for each meteorological element and buoy (see Table I). All data of the KMA buoys are quality controlled through a series of tests such as missing value test, physical limit test, step test, internal consistency test, and persistence test [42]. Differences in the height of the wind speed were overcome by using a 
TABLE I

Marine Meteorological Buoy Station Specification of KMA in the Seas Around the Korean Peninsula Including the Measurement Heights of Atmospheric and Oceanic Variables, Such as Air Temperature, Humidity, Wind, and Sea Surface Temperature, and the SHORTESt Distance of Each Buoy Station From the Coast of the Korean PEninsula

\begin{tabular}{|c|c|c|c|c|c|c|c|c|c|c|c|c|}
\hline \multirow{3}{*}{ Ocean } & \multicolumn{2}{|r|}{ Station } & \multicolumn{2}{|c|}{ Location } & \multicolumn{6}{|c|}{ Observation height $(\mathrm{m})$} & \multirow{3}{*}{ Depth (m) } & \multirow{3}{*}{$\begin{array}{l}\text { Distance } \\
\text { from land } \\
(\mathrm{km})\end{array}$} \\
\hline & \multirow{2}{*}{ Symbol } & \multirow{2}{*}{ Name } & \multirow{2}{*}{ Longitude } & \multirow{2}{*}{ Latitude } & \multicolumn{3}{|c|}{ Atmospheric } & \multicolumn{2}{|c|}{ Wind } & \multirow{2}{*}{$\begin{array}{c}\text { Sea } \\
\text { Temp. }\end{array}$} & & \\
\hline & & & & & Temp. & Humidity & Pressure & Speed & Direction & & & \\
\hline \multirow{6}{*}{ Yellow Sea } & Y1 & Deokjeokdo & $126^{\circ} 01^{\prime} 08^{\prime \prime} \mathrm{E}$ & $37^{\circ} 14^{\prime} 10^{\prime \prime} \mathrm{N}$ & 3.4 & 3.4 & 0.2 & 3.6 & 4.3 & 0.2 & 30 & 65 \\
\hline & $\mathrm{Y} 2$ & Incheon & $125^{\circ} 25^{\prime} 44^{\prime \prime} \mathrm{E}$ & $37^{\circ} 05^{\prime} 30^{\prime \prime} \mathrm{N}$ & 3.4 & 3.4 & 0.2 & 3.6 & 4.3 & 0.2 & 40 & 119 \\
\hline & Y3 & Oeyeondo & $125^{\circ} 45^{\prime} 00^{\prime \prime} \mathrm{E}$ & $36^{\circ} 15^{\prime} 00^{\prime \prime} \mathrm{N}$ & 3.4 & 3.4 & 0.2 & 3.6 & 4.3 & 0.2 & 47 & 78 \\
\hline & Y4 & Buan & $125^{\circ} 48^{\prime} 50^{\prime \prime} \mathrm{E}$ & $35^{\circ} 39^{\prime} 31^{\prime \prime} \mathrm{N}$ & 3.4 & 3.4 & 0.2 & 3.6 & 4.3 & 0.2 & 50 & 73 \\
\hline & Y5 & Chilbaldo & $125^{\circ} 46^{\prime} 37^{\prime \prime} \mathrm{E}$ & $34^{\circ} 47^{\prime} 36^{\prime \prime} \mathrm{N}$ & 3.4 & 3.4 & 0.2 & 3.6 & 4.3 & 0.2 & 33 & 55 \\
\hline & Y6 & Shinan & $126^{\circ} 14^{\prime} 30^{\prime \prime} \mathrm{E}$ & $34^{\circ} 44^{\prime} 00^{\prime \prime} \mathrm{N}$ & 3.4 & 3.4 & 0.2 & 3.6 & 4.3 & 0.2 & 25 & 16 \\
\hline \multirow{6}{*}{$\begin{array}{l}\text { Southern } \\
\text { region }\end{array}$} & $\mathrm{S} 1$ & Chujado & $126^{\circ} 08^{\prime} 28^{\prime \prime} \mathrm{E}$ & $33^{\circ} 47^{\prime} 37^{\prime \prime} \mathrm{N}$ & 2.9 & 2.9 & 0.3 & 4.0 & 4.0 & 0.1 & 85 & 49 \\
\hline & $\mathrm{S} 2$ & Marado & $126^{\circ} 02^{\prime} 00^{\prime \prime} \mathrm{E}$ & $33^{\circ} 05^{\prime} 00^{\prime \prime} \mathrm{N}$ & 3.9 & 3.4 & 0.2 & 3.9 & 4.4 & 0.4 & 130 & 53 \\
\hline & $\mathrm{S} 3$ & Seogwipo & $127^{\circ} 01^{\prime} 22^{\prime \prime} \mathrm{E}$ & $33^{\circ} 07^{\prime} 41^{\prime \prime} \mathrm{N}$ & 3.9 & 3.4 & 0.2 & 3.6 & 4.3 & 0.4 & 105 & 45 \\
\hline & $\mathrm{S} 4$ & Geomundo & $127^{\circ} 30^{\prime} 05^{\prime \prime} \mathrm{E}$ & $34^{\circ} 00^{\prime} 05^{\prime \prime} \mathrm{N}$ & 3.4 & 3.4 & 0.2 & 3.6 & 4.3 & 0.2 & 80 & 85 \\
\hline & S5 & Tongyeong & $128^{\circ} 13^{\prime} 30^{\prime \prime} \mathrm{E}$ & $34^{\circ} 23^{\prime} 30^{\prime \prime} \mathrm{N}$ & 3.4 & 3.4 & 0.2 & 3.6 & 4.3 & 0.2 & 55 & 54 \\
\hline & S6 & Geojedo & $128^{\circ} 54^{\prime} 00^{\prime \prime} \mathrm{E}$ & $34^{\circ} 46^{\prime} 00^{\prime \prime} \mathrm{N}$ & 3.4 & 3.4 & 0.2 & 3.6 & 4.3 & 0.2 & 87 & 28 \\
\hline \multirow{5}{*}{$\begin{array}{c}\text { East Sea / } \\
\text { Japan Sea } \\
\text { (EJS) }\end{array}$} & E1 & Ulsan & $129^{\circ} 50^{\prime} 29^{\prime \prime} \mathrm{E}$ & $35^{\circ} 20^{\prime} 43^{\prime \prime} \mathrm{N}$ & 3.9 & 3.4 & 0.2 & 3.6 & 4.3 & 0.4 & 145 & 52 \\
\hline & E2 & Pohang & $129^{\circ} 47^{\prime} 00^{\prime \prime} \mathrm{E}$ & $36^{\circ} 21^{\prime} 00^{\prime \prime} \mathrm{N}$ & 3.9 & 3.4 & 0.2 & 3.9 & 4.4 & 0.4 & 310 & 54 \\
\hline & E3 & Uljin & $129^{\circ} 52^{\prime} 28^{\prime \prime} \mathrm{E}$ & $36^{\circ} 54^{\prime} 25^{\prime \prime} \mathrm{N}$ & 3.9 & 3.4 & 0.2 & 3.6 & 4.3 & 0.4 & 700 & 42 \\
\hline & E4 & Donghae & $129^{\circ} 57^{\prime} 00^{\prime \prime} \mathrm{E}$ & $37^{\circ} 28^{\prime} 50^{\prime \prime} \mathrm{N}$ & 3.9 & 3.4 & 0.2 & 3.9 & 4.4 & 0.4 & 1518 & 43 \\
\hline & E5 & Ulleungdo & $131^{\circ} 06^{\prime} 52^{\prime \prime} \mathrm{E}$ & $37^{\circ} 27^{\prime} 20^{\prime \prime} \mathrm{N}$ & 3.9 & 3.4 & 0.2 & 3.9 & 4.4 & 0.4 & 2200 & 19 \\
\hline
\end{tabular}

conversion model for the standardization to a 10-m neutral wind speed.

\section{B. SAR Data}

To validate the high-resolution sea surface wind from SAR level-1 ground range detected (GRD) data in the coastal region around the Korean Peninsula, we collected Sentinel-1A/B data obtained by the ESA. The Sentinel-1A/B is equipped with a C-band SAR and its center frequency is $5.405 \mathrm{GHz}$. There are four acquisition modes, Stripmap (SM), Interferometric Wide swath (IW), Extra-Wide swath (EW), and Wave (WV), and each acquisition mode product is available as single-polarized ( $\mathrm{HH}$ and VV) data and other modes except for the WV mode are also available as dual-polarized $(\mathrm{HH}+\mathrm{HV}$ and $\mathrm{VV}+\mathrm{VH})$ data. We used Sentinel-1A/B IW mode vertical dual-polarized $(\mathrm{VV}+\mathrm{VH})$ data, the common mode of the Sentinel-1 data in the Korean marginal seas. The swath is approximately $250 \mathrm{~km}$, the pixel spacing of the GRD products including the NRCS is $10 \mathrm{~m}$, and the incidence angle ranges from $29.1^{\circ}$ to $46.0^{\circ}$. We collected 395 Sentinel-1A/B SAR images of IW mode vertical dual-polarized data (VV + VH) from May 1, 2015, to September 30,2017 as shown in the red boxes of Fig. 2. The SAR coverage includes the buoy locations in each coastal region as marked in blue circular dots and as shown in Fig. 2.

\section{Model Data and Elevation Data}

To calculate the sea surface wind from the Sentinel-1A/B IW mode data, wind direction information is required. In general for SAR wind retrieval, the wind direction data are obtained using

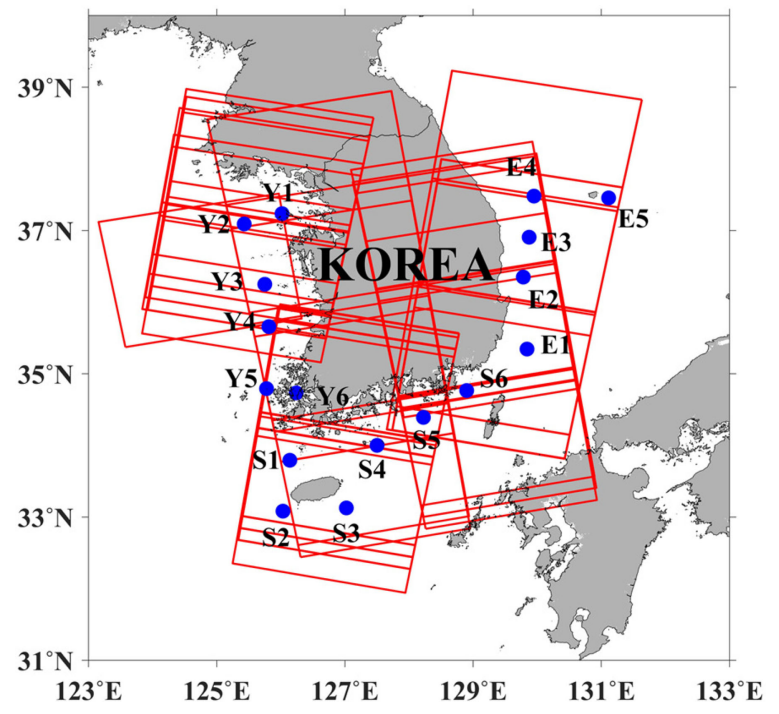

Fig. 2. Distribution of the Sentinel-1A/B IW mode vertical dual-polarized image including the KMA marine meteorological buoys from May 1, 2015, to September 30, 2017, where the blue circles and the black text around the circles indicate the location and symbol of the KMA marine meteorological buoys, respectively.

a method of extracting from the SAR images [43]-[45], calculating from quad-polarized $(\mathrm{HH}+\mathrm{HV}+\mathrm{VV}+\mathrm{VH})$ data [46], [47], or from external data (e.g., in situ measurements, scatterometric wind data, and numerical model data). However, when no ambient wind streak is visible in the SAR image because of atmospheric condition, it is not possible to directly extract the 
wind direction information from the SAR image. In addition, because the Sentinel-1A/B IW mode data are dual-polarized data, the quad-polarized approach is not valid. Therefore, in this study, we used European Centre for Medium-Range Weather Forecasts (ECMWF) reanalysis wind field data as an external input for wind direction data. The ECMWF reanalysis wind data, which are from a global atmospheric reanalysis model database, have been continuously produced every $6 \mathrm{~h}$ (0 UTC, 6 UTC, 12 UTC, and 18 UTC) with a spatial resolution of $80 \mathrm{~km}$. Sentinel-1A/B satellites observe the coastal region around the Korean Peninsula at 9 UTC during an ascending orbit and 21 UTC during a descending orbit, and the time difference between the reanalysis data and the SAR data is less than $3 \mathrm{~h}$.

To mask the land area in the SAR images, we used shuttle radar topography mission (SRTM) digital elevation model (DEM) data [48], [49]. The SRTM DEM data processed by NASA are land elevation data with an arc-second spatial resolution and include a near-global range of $56^{\circ} \mathrm{S}$ to $60^{\circ} \mathrm{N}$.

\section{METHODS}

\section{A. SAR Data Preprocessing}

To obtain an accurate sea surface wind, we preprocessed the NRCS of the Sentinel-1A/B IW mode data to mask land and ships and reduce the speckle noise. The remaining land pixels in the SAR image were masked using the SRTM DEM data.

The adaptive threshold method was used to detect ship pixels with a larger NRCS than the ocean pixels in the SAR image [50]-[53]. The adaptive threshold method is among the most widely used methods for target detection in SAR images and does not require high computational efficiency or additional data knowledge while continuously modifying the threshold based on the local characteristics of the observational region using target, guard, and background windows. These three windows were moved one pixel in the azimuth direction and range direction at a time across the whole Sentinel-1A/B image (see Fig. 3).

Speckle noise that degrades image quality is usually evident in the SAR image. Speckle noise has a multiplicative error and has to be removed before investigating the SAR image; otherwise, the speckle noise will affect the surrounding pixels and degrade the image quality [54]. In this study, we used a mean filter which is among the most widely used low-pass filters and shows excellent results for image smoothing [55], [56]. The remaining ocean pixels in the SAR image were ensemble averaged in a $21 \times 21$ moving window to reduce the speckle noise, and the final pixel spacing is given to $10 \mathrm{~m} \times 10 \mathrm{~m}$ after preprocessing.

\section{B. Retrieval of Wind Speed}

Fig. 4 shows a flow diagram for the sea surface wind retrieval procedure from the Sentinel-1A/B IW mode VV polarized data. All variables such as NRCS, incidence angle, and radar azimuth look angle were extracted from the Sentinel-1A/B IW mode VV polarized data. The NRCS data were then preprocessed to mask the land and ship pixels and reduce the speckle noise. ECMWF reanalysis wind fields were used to calculate the relative wind direction used as input data for the C-band GMFs [57]. Finally,

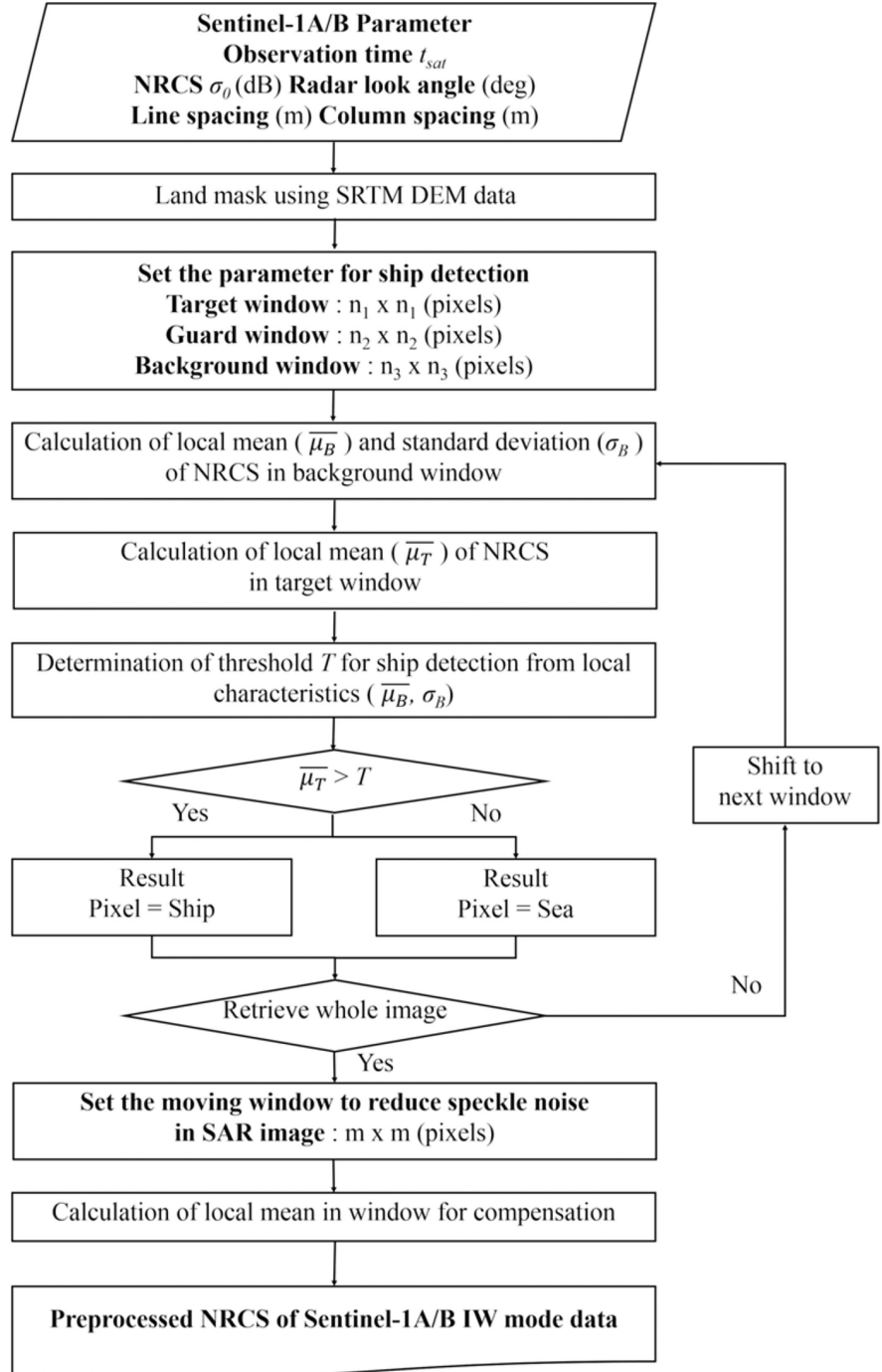

Fig. 3. Flowchart for preprocessing method of the Sentinel-1A/B IW mode data, including the land masking, ship masking using the adaptive threshold, and reduction of the speckle noise.

the preprocessed NRCS data along with the incidence angle and relative wind direction data were applied to yield the sea surface wind using the C-band GMFs.

The GMFs, depending on the wavelength and polarization state of the radar, are empirical relationships in terms of the NRCS, incidence angle, wind speed, and relative wind direction based on scatterometric data [58]. CMOD algorithms based on the C-band VV polarized data were used to calculate the sea surface wind from the Sentinel-1A/B IW mode VV polarized data. C-band GMFs are summarized as follows:

$\sigma_{0}=B_{0}\left(U_{10}, \theta\right)\left[1+B_{1}\left(U_{10}, \theta\right) \cos \varphi+B_{2}\left(U_{10}, \theta\right) \cos 2 \varphi\right]^{p}$

where $\sigma_{0}$ is the NRCS, $U_{10}$ is the 10 - $\mathrm{m}$ wind speed, $\theta$ is the incidence angle, and $\varphi$ is the relative wind direction that corresponds to the angle between the radar azimuth look angle and the wind direction. $B_{0}, B_{1}, B_{2}$, and $p$ are coefficients depending on $U_{10}$, $\theta$, and the C-band GMFs [27]-[32]. In this study, wind speeds 


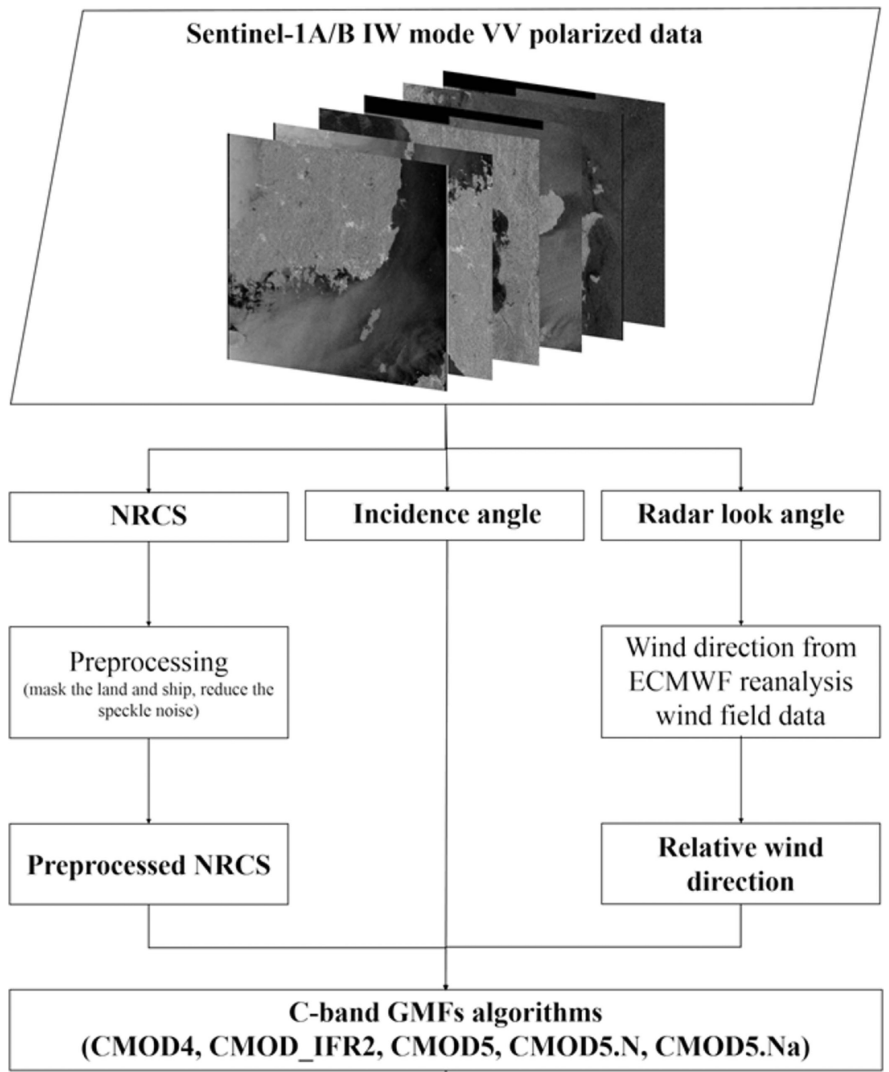

Retrieval of wind speed at a height of $10 \mathrm{~m}$

Fig. 4. Schematic description for sea surface wind retrieval from Sentinel1A/B IW mode data.

from all of the CMOD models, i.e., the CMOD4, CMOD_IFR2, CMOD5, CMOD5.N, and CMOD5.Na functions, were validated by comparison to in situ measurements.

We visualized CMOD functions based on the incidence angle range of the Sentinel-1A/B IW mode data from $29.1^{\circ}$ to $46.0^{\circ}$ (see Fig. 5). Fig. 5(a) and (b) shows the relationship between the relative wind direction and the NRCS calculated by all of the CMOD functions at an incidence angle of $29.1^{\circ}$ and $46.0^{\circ}$ and a wind speed of $20 \mathrm{~m} \cdot \mathrm{s}^{-1}$. Fig. 5(c) and (d) shows the estimated wind speed as a function of the NRCS at an incidence angle of $29.1^{\circ}$ and $46.0^{\circ}$ and a relative wind direction of $0^{\circ}$ using all of the CMOD functions. The anisotropy in the upwind/crosswind and the asymmetry in the upwind/downwind were well represented and these were consistent with the simulations of the CMOD functions in previous studies [59].

\section{10-m Wind Conversion}

The sea surface wind from the Sentnel-1A/B data represents the wind at a height of $10 \mathrm{~m}$; however, the wind speed of the KMA marine meteorological buoys data is measured at heights from 3.6 to $4.0 \mathrm{~m}$. Because of the different heights of the sea

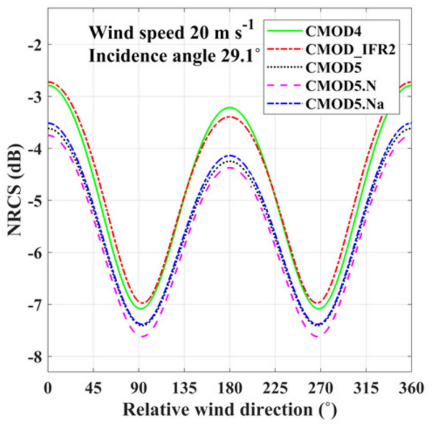

(a)

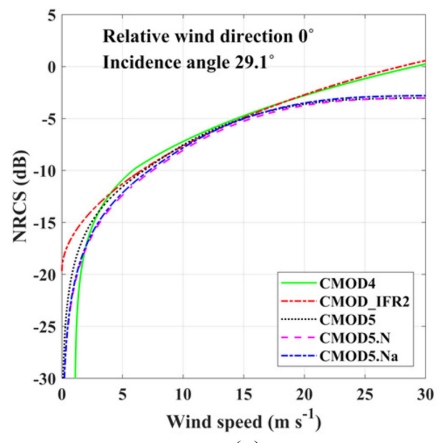

(c)

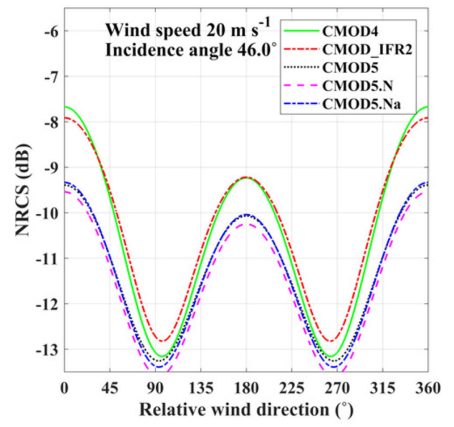

(b)

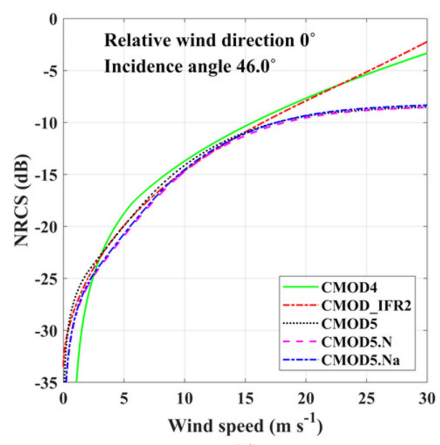

(d)
Fig. 5. Distribution of the estimated NRCS as a function of relative wind direction at a given incidence angle (a) $29.1^{\circ}$ and (b) $46.0^{\circ}$ with the wind speed of $20 \mathrm{~m} \cdot \mathrm{s}^{-1}$ using the CMOD functions, and distribution of the estimated NRCS as a function of wind speed at a given incidence angle (c) $29.1^{\circ}$ and (d) $46.0^{\circ}$ with the relative wind direction of $0^{\circ}$ using the CMOD functions.

surface wind from the Sentinel-1A/B data and the KMA marine meteorological buoys, it was necessary to convert the in situ wind speed to neutral wind at a 10-m height based on all meteorological variable measurements of the KMA buoys. We used the Liu-Katsaros-Businger (LKB) model to simulate the MABL with respect to the atmospheric and marine environment, to convert the in situ wind speed to a neutral wind at a height of $10 \mathrm{~m} \mathrm{[60],} \mathrm{[61].}$

The LKB model is designed to calculate the wind speed at a specific height using sea surface temperature, air temperature, humidity, air pressure, and wind speed and the observational heights of wind speed, air temperature, and humidity. The wind speed functional form of the LKB model is as follows:

$$
\frac{u-u_{s}}{u_{*}}=\frac{\ln \left(\frac{z}{z_{u}}\right)-\Psi_{u}}{k}
$$

where $u$ and $u_{s}$ denote the wind speed at a specific height and the reference height, respectively; $u_{*}$ represents the friction velocity; and $z$ and $z_{u}$ indicate the specific height and the observational height of the wind speed, respectively. The Von Karman constant $k$ was set at 0.4 [62]. $\Psi_{u}$ is the stability parameter that depends on the characteristics of the fluid, derived from the Businger-Dyer model as follows [63], [64]:

$$
\Psi_{u}=2 \ln \left[\frac{(X+1)}{2}\right]+\ln \left[\frac{\left(X^{2}+1\right)}{2}\right]-2 \tan ^{-1}[X]+\frac{\pi}{2}
$$




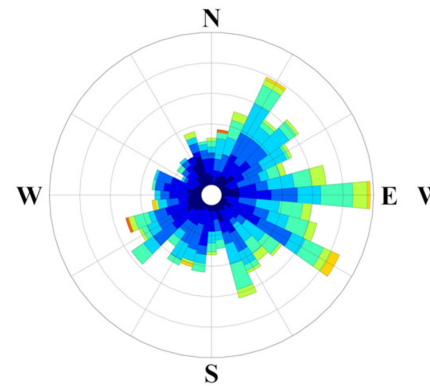

(a)

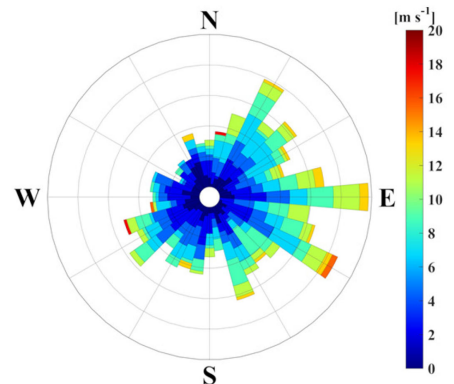

(b)
Fig. 6. Distribution of (a) in situ wind vectors data and (b) converted in situ wind vectors in meteorological convention using the LKB model from the KMA marine meteorological buoys of the matchup database in the seas around the Korean Peninsula.

where $X$ is $\left(1+a_{u} \xi\right)^{\frac{1}{4}}$ and $\xi$ is the ratio of the specific height $z$ and the Monin-Obukhov length $L$. We used a coefficient $a_{u}$ of 10, and the Monin-Obukhov length $L$ was derived using the potential temperature $T$, the specific humidity $Q$, the scaling potential temperature $\theta_{*}$, and the scaling specific humidity $q_{*}$ calculated from the relationships of heat flux, moisture flux, and friction velocity [61]. As a result of applying the LKB model to the in situ measurements, the in situ wind speed was converted to a 10-m neutral wind reflecting the marine atmospheric stratification. The wind speeds from buoy measurements at lower heights were converted to 10-m wind speeds which were higher than the original wind speed as shown in the directional histograms of the wind speeds, where the atmospheric convention of the wind direction was used, after the conversion procedure (see Fig. 6). These converted wind speeds were used to validate the accuracy of the SAR wind speeds for each CMOD model.

\section{Estimation of Wind Speed Errors}

To assess the accuracy of the satellite-observed wind speed quantitatively, statistical parameters, such as bias, root-meansquare error (RMSE), standard deviation (STD), and linear correlation coefficient $(R)$, were selected in this study as follows:

$$
\begin{aligned}
\text { bias } & =\frac{\sum_{i=1}^{N}\left(V_{i}-v_{i}\right)}{N}=\bar{V}-\bar{v} \\
\mathrm{RMSE} & =\sqrt{\frac{\sum_{i=1}^{N}\left(V_{i}-v_{i}\right)^{2}}{N}} \\
\mathrm{STD} & =\sqrt{\frac{\sum_{i=1}^{N}\left(V_{i}-v_{i}-\mathrm{Bias}\right)^{2}}{N-1}} \\
R & =\frac{\sum_{i=1}^{N}\left(V_{i}-\overline{V_{i}}\right)\left(v_{i}-\overline{v_{i}}\right)}{\left(\sigma_{\mathrm{sat}} \sigma_{\mathrm{in}-\mathrm{situ}}\right)(N-1)} \\
E_{\mathrm{com}} & =\sqrt{\mathrm{RMSE}^{2}+\mathrm{Bias}^{2}}
\end{aligned}
$$

where $V_{i}$ and $v_{i}$ denote the estimated wind speed and the in situ wind speed, respectively. $\bar{V}$ and $\bar{v}$ represent the average values of the Sentinel-1A/B wind speeds and in situ measurements, respectively; $\sigma_{\text {sat }}$ and $\sigma_{\text {in-situ }}$ indicate the STD of wind

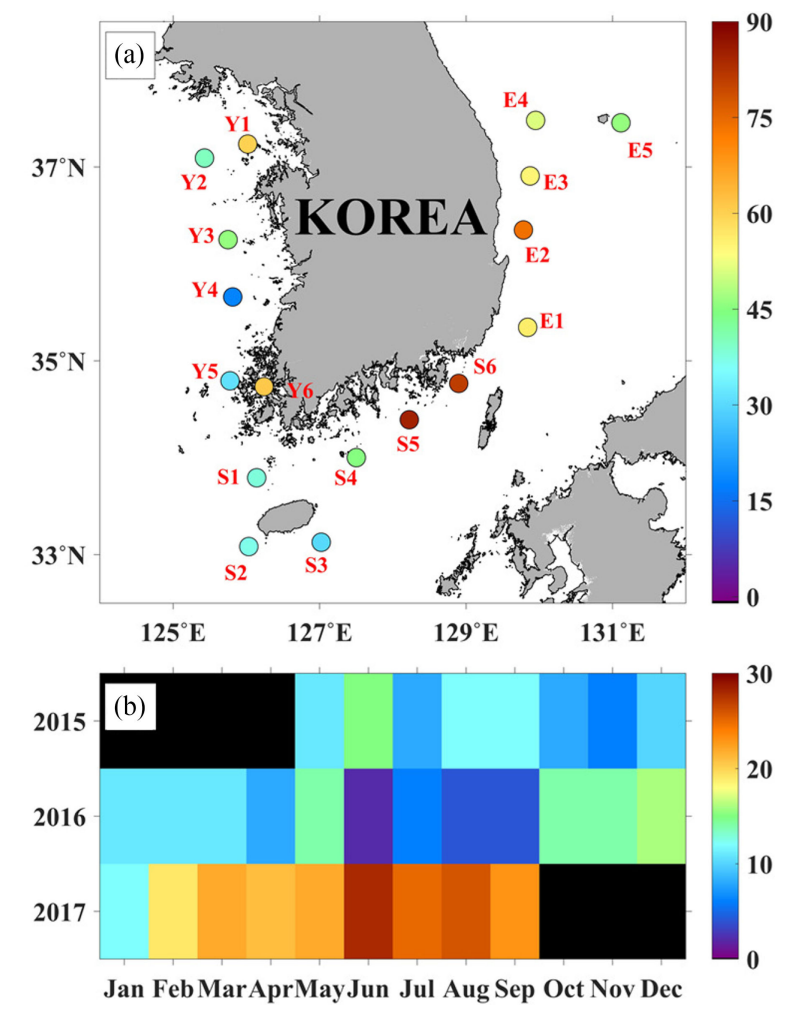

Fig. 7. (a) Number of the matchup data for each KMA marine meteorological buoys in the seas around the Korean Peninsula and (b) number of the Sentinel1A/B IW mode vertical dual polarized image acquisition from May 1, 2015, to September 30, 2017.

speeds from Sentinel-1A/B satellite and in situ measurements, respectively. Since both RMSE and bias errors are important, this study proposes a combined error, $E_{\text {com }}$, with the concept of combining the two errors as shown in (8).

\section{RESULTS}

\section{A. Matchup Data}

A matchup database was produced by collocating the Sentinel-1A/B IW mode data with the quality controlled in situ data of the KMA marine meteorological buoys within a spatial gap of approximately $20 \mathrm{~m}$ and a temporal interval of $1 \mathrm{~h}$. From May 1, 2015, to September 30, 2017, 395 Sentinel-1A/B IW mode images with VV polarization were collected. The number of matchups contained in one image of the Sentinel1A/B IW mode data ranged from 1 to as many as 4 because of a relatively large swath of approximately $250 \mathrm{~km}$. The total number of matchups amounted to 807 , which was composed of diverse contributions from stations in the eastern (E1-E5), western (Y1-Y6), and southern coastal regions (S1-S6). As shown in the colored circle dots in Fig. 7(a), the number of matchup points was the smallest as 18 at station Y4 in the western coastal region and the highest at 85 points at station S5 in the southern coastal region. The number of matchup points tended to increase as time passed from 2015 to 2017. This may be associated with the more frequent observations of Sentinel-1A/B 


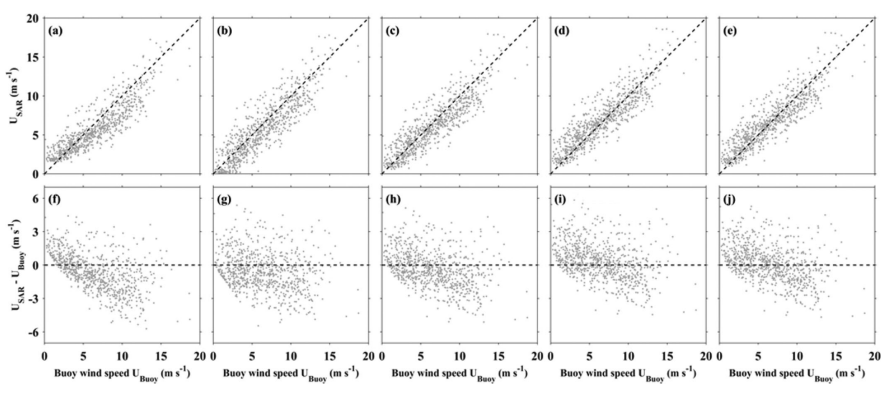

Fig. 8. Comparison of buoy wind speed with the wind speed derived from the Sentinel-1A/B using (a) CMOD4, (b) CMOD_IFR2, (c) CMOD5, (d) CMOD5.N, and (e) CMOD5.Na, and comparison of residuals (Sentienl$1 \mathrm{~A} / \mathrm{B}$ wind speed-buoy wind speed) of (f) CMOD4, (g) CMOD_IFR2, (h) CMOD5, (i) CMOD5.N, and (j) CMOD5.Na.

because Sentinel-1B was launched after Sentinel-1A in April 2016. Since February 2017, more than 15 matched up images were generated each month, and gradually increased to produce more matchup data during 2017 [see Fig. 7(b)]. The frequent and good-quality observations of Sentinel-1A/B enabled assessment of the accuracies of the Sentinel-1A/B wind speeds in the coastal regions, which had never been done before in the study area mainly because of a lack of SAR observations.

\section{B. Overall Accuracy of Wind Speeds}

The accuracies of the CMOD functions (CMOD4, CMOD_IFR2, CMOD5, CMOD5.N, and CMOD5.Na) were investigated by comparing the sea surface winds from the Sentinel-1A/B data and the in situ wind speeds in the coastal seas around the Korean Peninsula (see Fig. 8). As a result, the accuracy of the sea surface wind using each function of CMOD4, CMOD_IFR2, CMOD5, CMOD5.N, and CMOD5.Na showed the RMSEs of $1.83,1.82,1.69,1.68$, and $1.65 \mathrm{~m} \cdot \mathrm{s}^{-1}$, respectively, which can be regarded to be relatively small within the expected limit of the speed errors of less than $2.0 \mathrm{~m} \cdot \mathrm{s}^{-1}$. Regarding bias errors, the CMOD4, CMOD_IFR2, and CMOD5 model functions tended to underestimate the sea surface wind as compared to the in situ wind speed with bias errors of -0.64 , -0.59 , and $-0.38 \mathrm{~m} \cdot \mathrm{s}^{-1}$, respectively. In contrast, the CMOD5 models of CMOD5.N and CMOD5.Na tended to overestimate the sea surface wind derived from the Sentinel-1A/B data compared to the in situ wind speed of the buoy stations with biases of 0.31 and $0.14 \mathrm{~m} \cdot \mathrm{s}^{-1}$, respectively.

Under low wind conditions of less than $5 \mathrm{~m} \cdot \mathrm{s}^{-1}$, the sea surface winds from the Sentinel-1A/B data showed a tendency to be overestimated compared to the in situ wind speeds for all of the CMOD functions [see Fig. 8(f)-(j)]. To investigate the magnitude of errors under low wind conditions, we sampled the wind speeds below $5 \mathrm{~m} \cdot \mathrm{s}^{-1}$ and estimated the errors. The accuracy of CMOD4, CMOD_IFR2, CMOD5, CMOD5.N, and CMOD5.Na showed RMSEs of $1.24,1.54,1.41,1.73$, and $1.64 \mathrm{~m} \cdot \mathrm{s}^{-1}$, respectively, and bias errors of $0.49,-0.10,0.36,1.05$, and $0.93 \mathrm{~m} \cdot \mathrm{s}^{-1}$, respectively. The bias errors of the CMOD functions, except for that of CMOD_IFR2 which was weakly negative, were all positive, which implies somewhat of a lower capability of wind speed estimation under low wind speed conditions. Concluding with the RMSE only, that of CMOD4 seemed to be better than that of the other CMOD functions.

In the range of the wind speed higher than $10 \mathrm{~m} \cdot \mathrm{s}^{-1}$, the RMSE of CMOD4, CMOD_IFR2, CMOD5, CMOD5.N, and CMOD5.Na was approximately $2.49,2.17,2.19,1.89$, and $1.94 \mathrm{~m} \cdot \mathrm{s}^{-1}$, respectively, and the bias error was $-1.68,-1.08$, $-1.22,-0.54$, and $-0.80 \mathrm{~m} \cdot \mathrm{s}^{-1}$, respectively. An underestimation of wind speeds of this type in the high wind speed range commonly appeared for all of the functions as mentioned by previous studies [30], [65]. Concluding from both the RMSEs and bias errors, the CMOD5.N model function showed better performance than that of the other CMOD functions at wind speeds higher than $10 \mathrm{~m} \cdot \mathrm{s}^{-1}$.

However, fundamental differences of GMFs should be noted in terms of atmospheric stability effect in vertical extrapolation of buoy wind speeds. Since three GMFs (CMOD_IFR2, CMOD5.N, and CMOD5.Na) retrieve neutral wind speeds, the buoy wind speed should be extrapolated under the assumption of neutral mMABL condition as in this study [66]. One the contrary, both CMOD4 and CMOD5 retrieve a non-neutral wind speed [32], [66]-[68], which requires consideration of stability in the conversion procedure of wind speeds. The differences of these types can make it difficult to discuss degree of performances among the GMFs. Therefore, we investigated how large the wind speed errors could be reduced if the vertical extrapolation followed the stability conditions of the GMFs. As a result, the accuracies of CMOD4 and CMOD5 winds to non-neutral buoy winds with the consideration of the stability were weakly improved in terms of RMSE (from 1.83 and $1.69 \mathrm{~m} \cdot \mathrm{s}^{-1}$ (neutral) to $1.79 \mathrm{~m} \cdot \mathrm{s}^{-1}$ and $1.68 \mathrm{~m} \cdot \mathrm{s}^{-1}$ (non-neutral)) and bias errors (from $-0.64 \mathrm{~m} \cdot \mathrm{s}^{-1},-0.38 \mathrm{~m} \cdot \mathrm{s}^{-1}$ to $-0.57 \mathrm{~m} \cdot \mathrm{s}^{-1},-0.31 \mathrm{~m} \cdot \mathrm{s}^{-1}$ ), respectively. Nevertheless, the errors (RMSE, bias, and $E_{\text {com }}$ ) of CMOD5.Na neutral winds were lower than the non-neutral stability-considered winds of CMOD4 and CMOD5 in the seas around the Korean peninsula. Since it is difficult to calculate the stability in most oceans, SAR winds were compared with $10-\mathrm{m}$ neutral buoy winds in the following.

\section{Accuracy of Regional Wind Speeds}

The three seas around the Korean Peninsula have quite different characteristics in terms of water depth, bathymetry, islands, tides, tidal currents, tidal flats, coastlines, and so on. To investigate the accuracy of the sea surface wind derived from the Sentinel-1A/B data in each sea area, we classified the Y1-Y6 buoys, S1-S6 buoys, and E1-E5 buoys as buoys in the Yellow Sea, the southern region, and the EJS, respectively, and evaluated the accuracy of the CMOD functions used to retrieve the sea surface wind in each area (see Fig. 9).

Table II summarizes the accuracy of the sea surface wind from the Sentinel-1A/B IW mode data in the seas around the Korean Peninsula with respect to the RMSE, bias, STD, correlation coefficient, and $p$ value. In the EJS and southern regions, the CMOD5.Na function more accurately estimated compared to the other CMOD functions, and the CMOD5 function better estimated compared to the other CMOD functions in the Yellow 


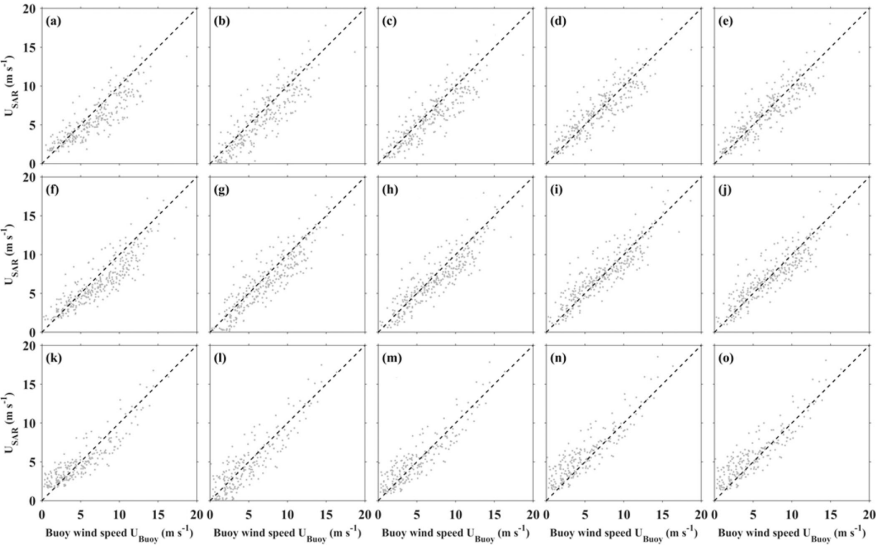

Fig. 9. Comparison of buoy wind speed with the wind speed derived from the Sentinel-1A/B using each CMOD functions including CMOD4, CMOD_IFR2, CMOD5, CMOD5.N, and CMOD5.Na in (a)-(e) EJS, (f)-(j) southern region, and $(\mathrm{k})-(\mathrm{o})$ Yellow Sea.

TABLE II

ACCURACY (RMSE, BIAS, STD, R, AND $P$ VALUE) OF THE WIND SPEED DERIVED From SENTINEL-1A/B IW MODE DATA USING CMOD4, CMOD_IFR2, CMOD5, CMOD5.N, AND CMOD5.Na IN THE EJS, THE SOUTHERN REGION, AND THE YELLOW SEA

\begin{tabular}{|c|c|c|c|c|c|}
\hline \multicolumn{2}{|c|}{ Region } & $\begin{array}{c}\text { East Sea / } \\
\text { Japan Sea } \\
\text { (EJS) }\end{array}$ & $\begin{array}{l}\text { Southern } \\
\text { region }\end{array}$ & $\begin{array}{l}\text { Yellow } \\
\text { Sea }\end{array}$ & Total \\
\hline \multicolumn{2}{|c|}{ Number of matchup } & 277 & 308 & 222 & 807 \\
\hline \multirow{5}{*}{ CMOD4 } & $\operatorname{RMSE}\left(\mathrm{m} \cdot \mathrm{s}^{-1}\right)$ & 1.93 & 1.91 & 1.56 & 1.83 \\
\hline & $\operatorname{Bias}\left(\mathrm{m} \cdot \mathrm{s}^{-1}\right)$ & -0.91 & -0.88 & 0.04 & -0.64 \\
\hline & $\operatorname{STD}\left(\mathrm{m} \cdot \mathrm{s}^{-1}\right)$ & 1.71 & 1.69 & 1.56 & 1.71 \\
\hline & Corr. & 0.87 & 0.88 & 0.89 & 0.88 \\
\hline & $p$ value & $8.0 \mathrm{e}-85$ & $6.5 e-103$ & $1.5 \mathrm{e}-76$ & $1.6 \mathrm{e}-264$ \\
\hline \multirow{5}{*}{ CMOD_IFR2 } & $\operatorname{RMSE}\left(\mathrm{m} \cdot \mathrm{s}^{-1}\right)$ & 1.94 & 1.80 & 1.67 & 1.82 \\
\hline & $\operatorname{Bias}\left(\mathrm{m} \cdot \mathrm{s}^{-1}\right)$ & -0.80 & -0.67 & -0.20 & -0.59 \\
\hline & $\operatorname{STD}\left(\mathrm{m} \cdot \mathrm{s}^{-1}\right)$ & 1.77 & 1.67 & 1.67 & 1.72 \\
\hline & Corr. & 0.87 & 0.89 & 0.89 & 0.89 \\
\hline & $p$ value & $3.7 \mathrm{e}-87$ & $5.3 e-107$ & $5.6 e-75$ & $2.3 e-272$ \\
\hline \multirow{5}{*}{ CMOD5 } & $\operatorname{RMSE}\left(\mathrm{m} \cdot \mathrm{s}^{-1}\right)$ & 1.79 & 1.70 & 1.54 & 1.69 \\
\hline & $\operatorname{Bias}\left(m \cdot s^{-1}\right)$ & -0.64 & -0.54 & 0.17 & -0.38 \\
\hline & $\operatorname{STD}\left(\mathrm{m} \cdot \mathrm{s}^{-1}\right)$ & 1.67 & 1.61 & 1.53 & 1.65 \\
\hline & Corr. & 0.87 & 0.89 & 0.89 & 0.89 \\
\hline & $p$ value & $1.4 \mathrm{e}-88$ & $3.6 \mathrm{e}-109$ & $6.5 \mathrm{e}-79$ & $1.0 \mathrm{e}-277$ \\
\hline \multirow{5}{*}{ CMOD5.N } & $\operatorname{RMSE}\left(\mathrm{m} \cdot \mathrm{s}^{-1}\right)$ & 1.68 & 1.62 & 1.76 & 1.68 \\
\hline & $\operatorname{Bias}\left(m \cdot \mathrm{s}^{-1}\right)$ & 0.05 & 0.15 & 0.87 & 0.31 \\
\hline & $\operatorname{STD}\left(\mathrm{m} \cdot \mathrm{s}^{-1}\right)$ & 1.67 & 1.62 & 1.53 & 1.65 \\
\hline & Corr. & 0.87 & 0.89 & 0.89 & 0.89 \\
\hline & $p$ value & $1.4 \mathrm{e}-88$ & $6.3 e-109$ & $7.9 \mathrm{e}-79$ & $3.4 \mathrm{e}-277$ \\
\hline \multirow{5}{*}{ CMOD5.Na } & $\operatorname{RMSE}\left(\mathrm{m} \cdot \mathrm{s}^{-1}\right)$ & 1.66 & 1.61 & 1.67 & 1.65 \\
\hline & $\operatorname{Bias}\left(\mathrm{m} \cdot \mathrm{s}^{-1}\right)$ & -0.13 & -0.04 & 0.71 & 0.14 \\
\hline & $\operatorname{STD}\left(\mathrm{m} \cdot \mathrm{s}^{-1}\right)$ & 1.66 & 1.61 & 1.52 & 1.64 \\
\hline & Corr. & 0.88 & 0.90 & 0.90 & 0.89 \\
\hline & $p$ value & $9.3 \mathrm{e}-89$ & $2.3 \mathrm{e}-109$ & $3.6 \mathrm{e}-79$ & $3.2 \mathrm{e}-278$ \\
\hline
\end{tabular}

Sea. The overall tendency of the biases is that all of the CMOD functions produced their smallest errors in the EJS and the values changed to positive values in the Yellow Sea. This suggests some possibility of the potential effects of basin characteristics in the errors of the SAR wind speed, as discussed in the following sections.

To understand the accuracy with respect to areas and CMOD functions, we present Fig. 10. RMSE and bias error are accuracy parameters that indicate the deviation including the bias error

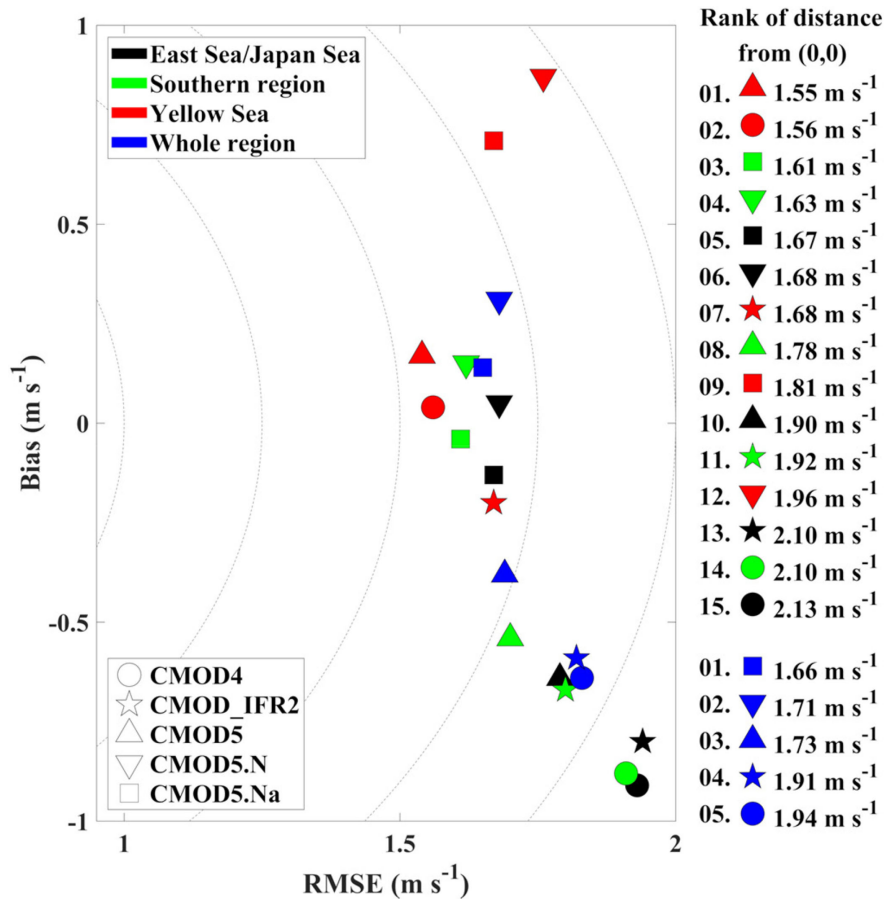

Fig. 10. Scatter plot of RMSE and bias errors for each region (East/Japan Sea, southern region, the Yellow Sea) and whole region for CMOD models (CMOD4, CMOD_IFR2, CMOD5, CMOD5.N, and CMOD5.Na), where the dotted contours represent the constant values of the combined errors using RMSE and bias.

and the tendency of underestimation and overestimation, respectively. Hence, we calculated $E_{\text {com }}$ variable, the distance from the origin that bias error and RMSE are zero, by the weight equivalent to RMSE and bias error. CMOD5 estimated more accurately in the Yellow Sea and CMOD5.Na estimated more accurately in the southern region, the EJS, and whole region than the other CMOD functions. In contrast, CMOD5.N estimated more inaccurately in the Yellow Sea and CMOD4 estimated more inaccurately in the southern region, the EJS, and whole region than the other CMOD functions.

\section{Wind Speed Errors of CMOD Models}

Comparison of five blue symbols over the whole regions in Fig. 10 reveals that CMOD5.Na (blue rectangle) shows the smallest combined error of about $1.66 \mathrm{~m} \cdot \mathrm{s}^{-1}$ and CMOD4 (blue circle) shows the largest combined error of about $1.94 \mathrm{~m} \cdot \mathrm{s}^{-1}$. Since CMOD_IFR2 is a default model of Sentinel-1A/B, we chose both the CMOD_IFR2 and CMOD5.Na to investigate peculiar characteristics of the errors and the dependence of SAR wind speed errors on the in situ wind speeds. As described previously, most of the functions tended to overestimate the SAR wind speeds under low wind conditions, while they underestimated the SAR winds under high wind conditions. It is inferred that the error characteristics should have a negative relation with the wind speed. The tendency of this type was investigated for the three coastal regions (eastern, southern, and western) of the coastline surrounding the Korean Peninsula. 

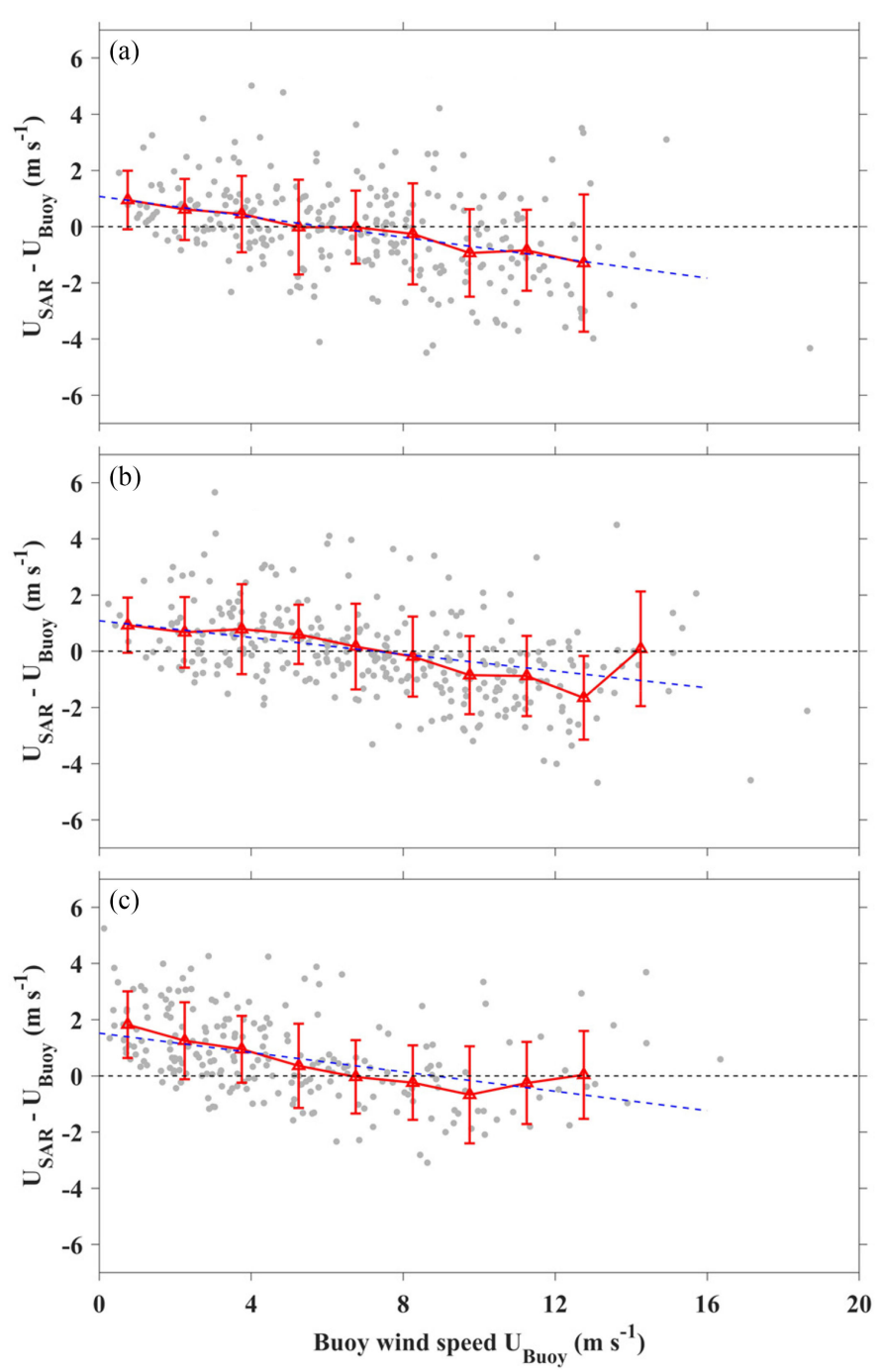

Fig. 11. Comparison of residuals (Sentienl-1A/B wind speed-buoy wind speed) using CMOD5.Na in (a) EJS, (b) southern region, and (c) Yellow Sea, where the red bars and blue-dashed line represent the STDs of wind speed errors for each interval and a least-squared fit to a linear function.

Fig. 11 shows the accuracy and the trend of the sea surface wind derived from the Sentinel-1A/B data using CMOD5.Na compared to the in situ wind speed for each sea area. In the case of the Yellow Sea, obvious negative relationship and overestimation of the wind speed differences with respect to buoy wind speed in Fig. 11(c) is probably related to the unequal distribution of the number of buoy wind speeds, more concentrated at low wind speeds of less than $5 \mathrm{~m} \cdot \mathrm{s}^{-1}$ than high winds. At a wind speed higher than $10 \mathrm{~m} \cdot \mathrm{s}^{-1}$, the negative biases were appeared for the three regions.

Fig. 12 shows the differences between the SAR wind speeds, estimated using the CMOD_IFR2 function, and buoy wind speeds (SAR minus buoy) as a function of buoy wind speed for each coastal region. Given a wind speed lower than $5 \mathrm{~m} \cdot \mathrm{s}^{-1}$, the accuracy for the EJS, the southern region, and the Yellow Sea showed RMSEs $\left(1.48-1.58 \mathrm{~m} \cdot \mathrm{s}^{-1}\right)$ and biases $(-0.37$ to $\left.0.13 \mathrm{~m} \cdot \mathrm{s}^{-1}\right)$. Although the errors are greatly reduced in a low
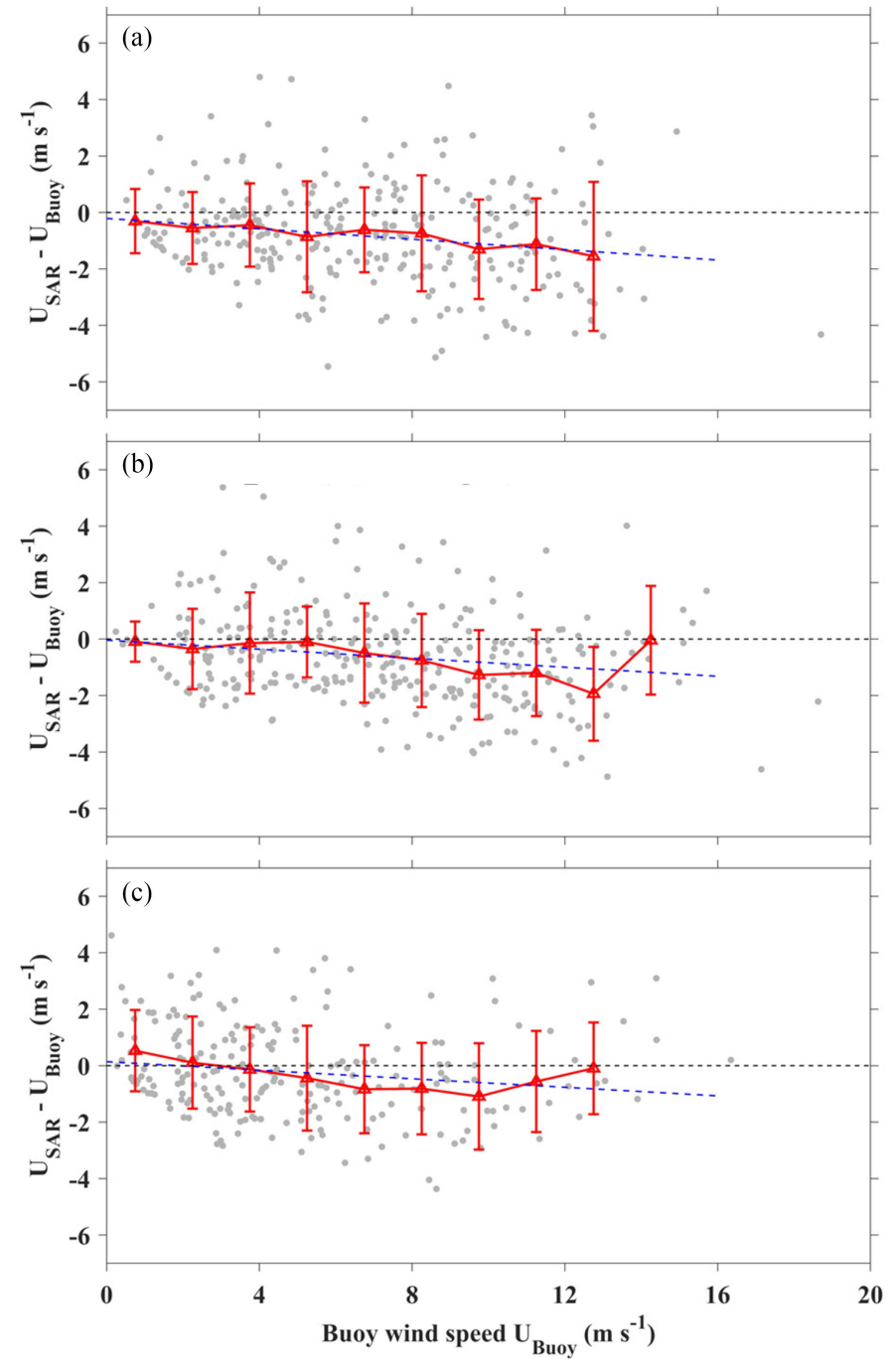

Fig. 12. Comparison of residuals (Sentienl-1A/B wind speed-buoy wind speed) using CMOD_IFR2 in (a) EJS, (b) southern region, and (c) Yellow Sea, where the red bars and blue-dashed line represent the STDs of wind speed errors for each interval and a least-squared fit to a linear function.

wind speed range as compared with the results of CMOD5.Na function, all of the scatters of the wind differences showed a similar characteristic of a negative trend of SAR wind speed with respect to in situ wind speed (see Fig. 12). This implies that the SAR wind speeds are predominantly underestimated within at high wind speeds; thus, careful use is needed during high wind conditions such as a typhoon period. Under extreme wind conditions like hurricane or typhoon, cross-polarized SAR measurements and a combined co- and cross-polarized SAR measurements can be used to overcome the underestimation of high wind speeds in VV mode [65], [69].

In the case of CMOD5.Na function, such a negative tendency induced by overestimation and underestimation seems to be more amplified than that of the CMOD_IFR2 function for the three coastal regions as shown in the slopes of the least-squared fits (see Fig. 11). At wind speeds less than $5 \mathrm{~m} \cdot \mathrm{s}^{-1}$ in the Yellow Sea, the accuracy of the CMOD_IFR2 function presented 
significantly smaller bias than that of CMOD5.Na. The RMSE values of the CMOD5.Na were higher than that of the CMOD_IFR2. In the Yellow Sea, the combined error of CMOD_IFR2 with seventh rank was evaluated to be smaller than that of CMOD5.Na with ninth rank in Fig. 10. Thus, this suggests that the comparisons of the model performances should be comprehensively done by considering all aspects of the errors such as RMSE, bias, STD, and their combined errors.

At high wind speeds $\left(>10 \mathrm{~m} \cdot \mathrm{s}^{-1}\right)$, the wind speed differences of the CMOD5.Na function seem to be reduced, showing its smallest value in the Yellow Sea. This proves the better performance of the CMOD5.Na function at high wind speeds as described by Verspeek et al. [32]. However, overall tendency of the wind speed differences presented not only negative trends but also a significant underestimation of wind speeds for CMOD5.Na as well as most GMFs at high winds. Concerning the systematic pattern of these negative residuals, previous literature has mentioned about their potential explanations using scatterometer wind data as well as SAR data. Under high wind condition, attenuation by rain was reported to reduce the signal causing an underestimation of the wind speed by up to $10 \mathrm{~m} \cdot \mathrm{s}^{-1}$ for $30 \mathrm{~m} \cdot \mathrm{s}^{-1}$ winds and $25 \mathrm{~mm} \cdot \mathrm{h}^{-1}$ rain. [70]. One of other characteristic reasons of the underestimation of CMOD4 high winds above $20 \mathrm{~m} \cdot \mathrm{s}^{-1}$ was explained by the choice of the analogue-to-digital converter settings of the SAR system [6], [71]-[73].

\section{E. Effect of Depth on Wind Speed Errors}

To investigate the effect of water depth on the SAR wind speed errors, the CMOD5.Na function was selected by considering. Indeed, as previously described, this GMF has better performance with relatively small RMSE and bias errors than those of the other functions in the overall coastal region around the Korean Peninsula. Fig. 13 shows the relation between the wind speed differences (SAR_-in situ) and water depth at each buoy station of the matchup database. Although there are some positive or negative differences, the peculiar characteristics of the differences are difficult to detect as shown in the small amplitudes of the mean errors, denoted in circles, particularly at depths greater than $40 \mathrm{~m}$. However, they tended to increase with positive differences as the water depth decreased as shown in Fig. 13. This implies that the mean of the SAR winds is overestimated by $0.5-1.5 \mathrm{~m} \cdot \mathrm{s}^{-1}$ in the shallow coastal region. The RMSE of the SAR-derived wind speeds amounted to $1.84 \mathrm{~m} \cdot \mathrm{s}^{-1}$ at a water depth shallower than $40 \mathrm{~m}$, which was also accompanied by a significant bias of approximately $1.01 \mathrm{~m} \cdot \mathrm{s}^{-1}$. However, the bias error was dominantly reduced to approximately $-0.03 \mathrm{~m} \cdot \mathrm{s}^{-1}$ at water depths greater than $40 \mathrm{~m}$.

This result is consistent with that of previous studies, which noted the effect of bathymetry on the generation of the convergence and divergence zones as well as the effect of the bathymetry-current interaction on changes in wind-driven sea surface wave spectra and the resulting backscatter variations in the microwave radar images [74]-[79]. When calculating the sea surface wind from SAR data using GMFs, it is assumed that the backscattering coefficients, as a representative indica-

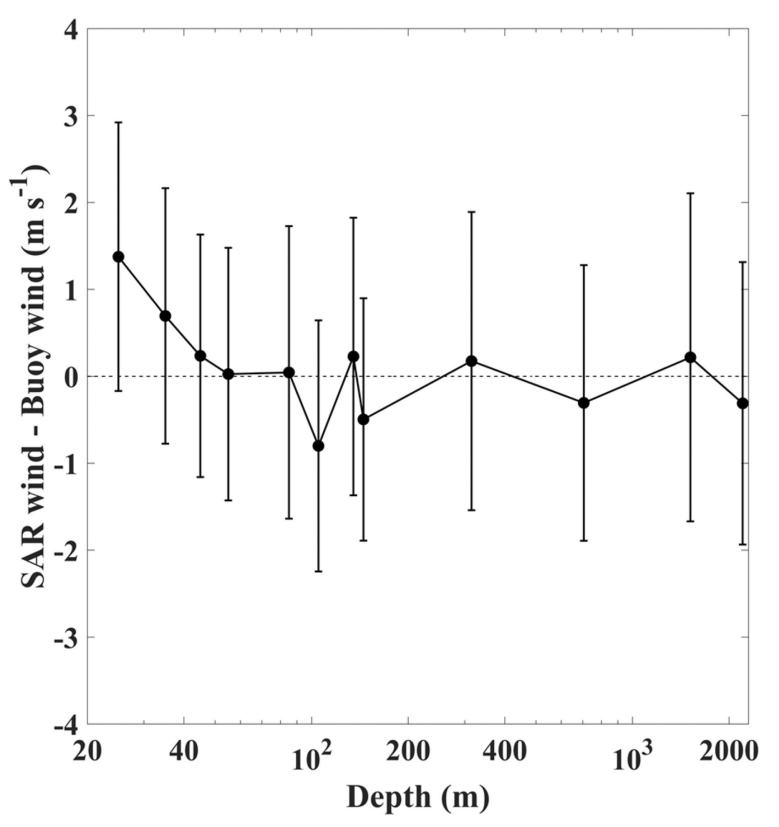

Fig. 13. Distribution of residuals (Sentienl-1A/B wind speed-buoy wind speed) using CMOD5.Na with water depth of the KMA marine meteorological buoys, where the red bars represent the STDs of wind speed errors for each interval.

tor of the sea surface roughness, are dominant by the ocean surface wind vectors. However, at shallow water depths, the sea surface roughness can also be affected by the bathymetry [80], [81]. There are also other possible reasons for modification of the backscattering such as a surface-stress-induced effect of the oceanic current as shown in scatterometric wind vectors in the warm and cold core rings of the Gulf Stream region [7], [11], [82].

The water depth of the buoy stations in the Yellow Sea is largely shallow $(30-50 \mathrm{~m})$ and less than that of the EJS (145$2200 \mathrm{~m}$ ) and the southern coastal region $(55-130 \mathrm{~m})$ as listed in Table I and shown in Fig. 1(c). The distinctive water depths illustrate a possibility that the sea surface roughness is modified by sea surface winds as well as other elements such as bathymetry. The bathymetry is expected to contribute to the errors related to the overestimation of the wind speed because of the enhanced NRCS values. Therefore, the potential sources of SAR wind errors need to be primarily understood considering the characteristics of the local sea area such as the shallow region of the Yellow Sea.

In the coastal region around the Korean peninsula, the penetration length of the atmosphere due to sea breezes is about 15-30 km [83]. Since the marine buoys are located much far from the coastal line in the Yellow Sea than the EJS by $52 \mathrm{~km}$ on average (16-119 km) as shown in Fig. 1(a) and Table I, the distance itself of the buoy locations from the coastline is thought to be not a main cause of the wind errors related to the land/sea breeze. In addition, Sentinel-1A/B observation times, at 6:00 and 18:00 by local time, are inappropriate for the investigation of the contribution of the land/sea breeze to the wind errors. 


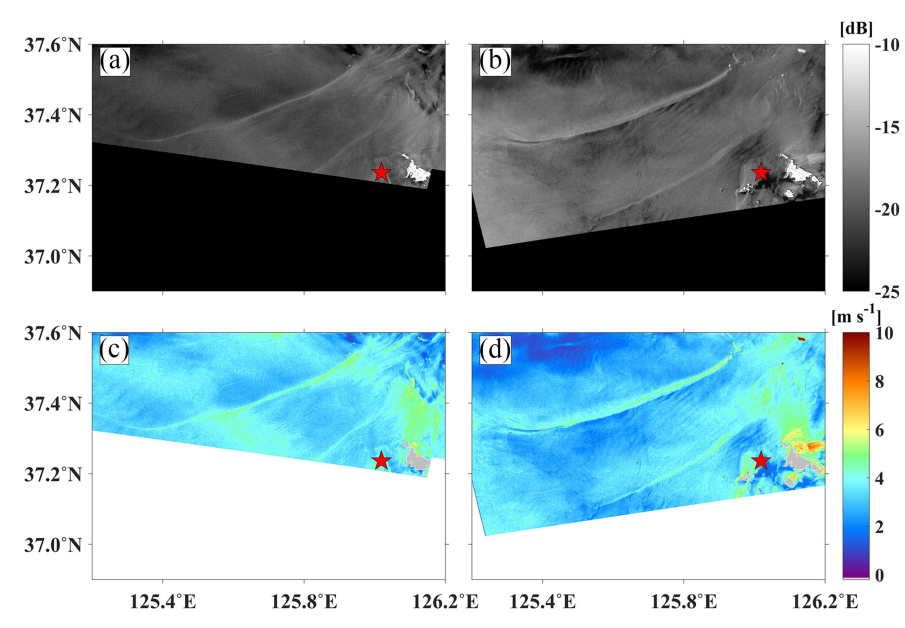

Fig. 14. NRCS of subscene of the Sentinel-1A/B images including the sand ridge in Gyeonggi Bay, which is located in the Eastern part of the Yellow Sea off the Western coast of the Korean Peninsula, on (a) May 6, 2017, and (b) May 19, 2017, and wind speed estimation from using CMOD5.Na algorithm on (c) May 6, 2017, and (d) May 19, 2017, where the red star indicates the Y1 KMA marine meteorological buoys.

\section{F. Effect of Sand Ridge}

Fig. 14(a) and (b) shows the NRCS images of Sentinel-1A/B on May 6, 2017, and on May 19, 2017 in Gyeonggi Bay off the western coast of the Korean Peninsula in the Yellow Sea. The spatially dominated high NRCS values, with elongated shapes from the northeast to the southwest at a zonal range between $125.4^{\circ} \mathrm{E}$ and $126.0^{\circ} \mathrm{E}$, correspond to a well-developed sand ridge. The sand ridge of this region is generated by the strong tidal current at shallow water depths rather than wind speed [84].

The spatial distribution of the wind speed, estimated from the Sentinel-1B image on May 6, 2017, as shown in Fig. 14(c), shows wind speeds of approximately $4.86 \mathrm{~m} \cdot \mathrm{s}^{-1}$ over the elongated sand ridge. This feature is in contrast to the relatively low wind speed values of the surrounding pixels of approximately $2.75 \mathrm{~m} \cdot \mathrm{s}^{-1}$ [see Fig. 14(c)]. The second image of wind speed exhibits the same tendency with high wind speeds $\left(4.64 \mathrm{~m} \cdot \mathrm{s}^{-1}\right)$ over the sand ridge at similar positions on May 19, 2017, which is in contrast with the wind speed of the surrounding pixels of approximately $2.42 \mathrm{~m} \cdot \mathrm{s}^{-1}$ [see Fig. 14(d)]. The differences across the sand ridge amount to $2 \mathrm{~m} \cdot \mathrm{s}^{-1}$, which is a tremendously overestimated, greater than $100 \%$ error as compared to the real wind speed. The errors of wind speeds from the NRCS are associated with diverse sources such as a sand ridge of this type, bathymetry, and oceanic currents.

As shown by the red asterisk in Fig. 14, the buoy position is 20-50 km away from the sand ridge, which is represented by two elongated features in the north. Scrutiny of the location of the KMA marine meteorological buoys and environmental factors confirmed no peculiar effects from sand ridges as potential error sources. Also, the bright areas and stripe-like features near the buoy (red star) in Fig. 14(d) seemed to be related to orographyinduced wind intensification and wind-induced streaks. Therefore, the wind speeds of the buoy station are not likely to be affected by the sand ridges. The observed wind speeds in this buoy were 4.02 and $3.40 \mathrm{~m} \cdot \mathrm{s}^{-1}$ on May 6 and 10, 2017, respectively.

\section{G. Effect of Wind Direction on Wind Speed Error}

As described earlier, all of the CMOD models need the input of wind direction prior to the estimation of the wind speeds. It is noteworthy that the accuracy of the retrieved wind speed is associated with an accurate value of wind direction. If the wind-induced streaks appear on the SAR images, information on wind direction can be obtained from the analysis methods such as Fourier transform spectrum, wavelet analysis, or local gradient [43]-[47]. In this study, all of SAR images did not necessarily reveal the adequate wind-related streaks. Therefore, the ECMWF wind directions were used in the CMOD models, which may give a rise to additional errors of the estimated wind speeds. Both time intervals and relatively large distance of ECMWF grids from the buoy stations may also cause the inaccurate wind directions, especially at the coastal regions of the Korean peninsula with very complicated coastlines.

In order to understand a potential impact of the different input of wind direction in the CMOD model, wind speed ratios with respect to the relative wind directions at a given NRCS are investigated. Fig. 15(a) presents the wind speeds estimated from the CMOD5.Na model for given NRCS values and relative wind directions from $-180^{\circ}$ to $180^{\circ}$. It should be noted that the estimated wind speed ratios, divided by the minimum value of wind speeds for a given NRCS value, indicate high contribution of the relative wind direction to the generation of remarkable wind speed ratios up to 2 [see Fig. 15(b)]. The averages of wind speed ratios with respect to wind direction differences show a wave-like feature with crests $(\sim 1.8)$ and troughs $(1.0-1.2)$ [see Fig. 15(c)].

Fig. 15(d) exhibits the wind speed differences between SAR winds and buoy wind measurements (SAR-buoy) as a function of wind direction differences between buoy and ECMWF (buoy-ECMWF). When the wind direction differences are small with values of less than $20^{\circ}$, the estimated wind speeds tend to be similar to the observed wind speeds yielding low values of less than $0.1 \mathrm{~m} \cdot \mathrm{s}^{-1}$. However, as the wind direction difference increases toward $90^{\circ}$, the mean values of wind speed errors increase up to about $1.2 \mathrm{~m} \cdot \mathrm{s}^{-1}$. The variations of the errors [see Fig. 15(d)] are quite a similar to the predicted ratios as shown in the experimental results of CMOD5.Na model [see Fig. 15(c)]. However, these direction differences are not directly compared with the ratios from model simulation. Fig. 15(d) suggests that wind speed differences are closely related to input of the wind direction in the model.

Fig. 15(e) shows the wind speed difference between SAR and buoy winds as a function of the direction difference between the ECMWF wind direction and the look angle. When the relative wind direction is $0^{\circ}$, the satellite shows the maximum value of about $0.9 \mathrm{~m} \cdot \mathrm{s}^{-1}$ with a positive peak. By contrast, when it is $\pm 90^{\circ}$, it shows negative peaks of about -0.5 and $-0.7 \mathrm{~m} \cdot \mathrm{s}^{-1}$, respectively. According to the result of Fig. 15(c), when the wind direction of the buoy corresponds to cross wind $\left( \pm 90^{\circ}\right)$, 

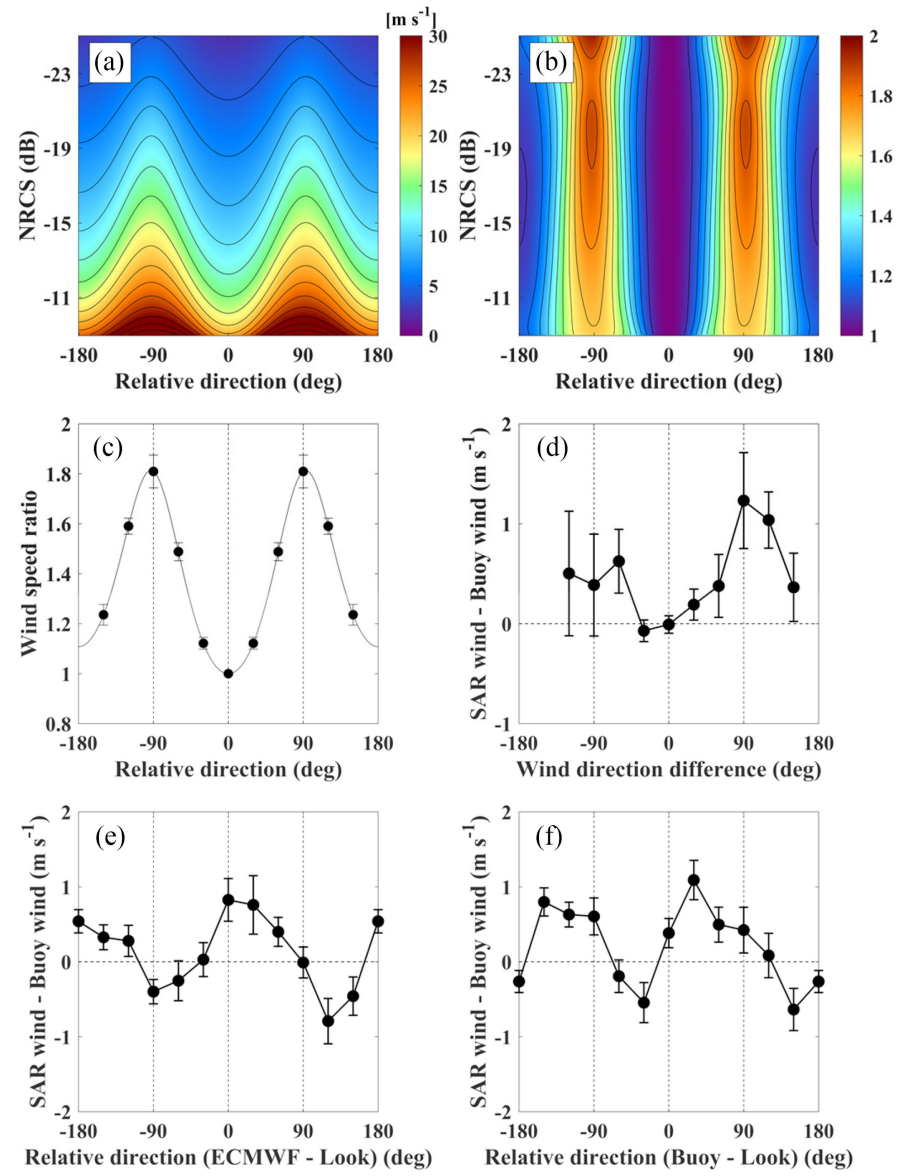

Fig. 15. Distributions of (a) estimated wind speeds $\left(\mathrm{m} \cdot \mathrm{s}^{-1}\right)$ as a function of the NRCS $(\mathrm{dB})$ and relative wind direction $\left(^{\circ}\right)$ using the CMOD5.Na algorithm and (b) ratios of wind speeds divided by the minimum value of wind speeds for a given NRCS value. (c) Average of wind speed ratio of (b) as a function of wind direction, (d) wind speed differences between SAR wind and buoy wind (SAR - buoy) as a function of wind direction difference (buoy-ECMWF), wind speed differences between SAR wind and buoy wind as a function of relative direction: (e) ECMWF minus look angle and (f) buoy wind direction minus look angle, where the error bars represent mean error $(\sigma / \sqrt{\mathbf{n}-\mathbf{1}}, N$ : the number of data points).

the wind differences obtained by subtracting the wind ( $y$-axis) from the SAR wind must be zero or negative, because the wind speed for a given NRCS should reach the maximum at cross winds. The result of Fig. 15(e) shows good agreement with the relationship of this type in Fig. 15(c).

The directions of ECMWF winds as 10-m neutral wind are different from that of the buoy wind vectors because of the different heights as well as stability effect in the MABL [11]. Investigation of air-sea stability of the matchup points in this study showed that most of collocated positions $(62.7 \%)$ were under an unstable condition. In this case, the ECMWF neutral wind direction is deflected on the right side of the buoy wind direction as evidenced in Park et al. [11]. So, the deflected angles should be positive in the oceanographic convention as the buoy wind direction is biased on the left of the ECMWF wind direction. Therefore, the overall pattern of Fig. 15(e) appears to be shifted in the positive angle direction by $30^{\circ}$ in Fig. 15(f). This analysis should be noted in that the errors of satellite-
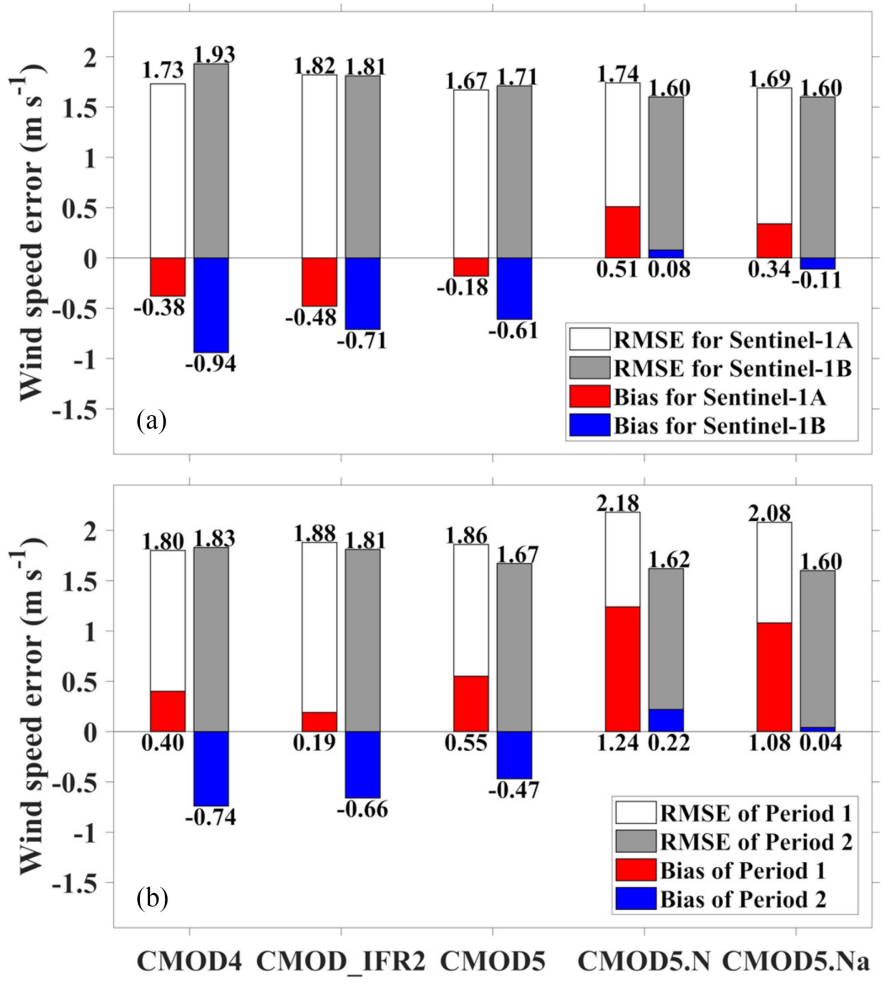

Fig. 16. RMSE and bias errors of wind speeds from CMOD models (CMOD4, CMOD_IFR2, CMOD5, CMOD5.N, and CMOD5.Na) for (a) Sentinel-1A and Sentinel-1B, (b) for the period 1 (from May 1, 2015, to November 25, 2015) and period 2 (from November 25, 2015, to September 30, 2017), where the numbers above (below) the bars represent the RMSE (bias) errors.

observed wind field can be understood quantitatively in relation to stability conditions in a MABL.

\section{H. Effect of Sentinel-1A/B Sensors and Calibration}

To compare the accuracy between Sentinel-1A and Sentinel$1 \mathrm{~B}$ wind speeds, we classified the matchup database by each satellite and tried to assess the RMSE and bias errors separately according to the five model functions as shown in Fig. 16(a). The numbers of the matchup points of Sentinel-1A and Sentinel-1B was 438 and 369, respectively. Both the smallest and the highest RMSEs, of about $1.60 \mathrm{~m} \cdot \mathrm{s}^{-1}$ (CMOD5.Na) and $1.93 \mathrm{~m} \cdot \mathrm{s}^{-1}$ (CMOD4), was found not from Sentinel-1A (white bars) but from Sentinel-1B (gray bars) [see Fig. 16(a)]. In the case of bias errors, Sentinel-1A showed relatively smaller errors for the first three models (CMOD4, CMOD_IFR2, CMOD5) than Sentinel1B. However, the bias errors are remarkably reduced in the cases of CMOD5.N $\left(0.08 \mathrm{~m} \cdot \mathrm{s}^{-1}\right)$ and CMOD5.Na $\left(-0.11 \mathrm{~m} \cdot \mathrm{s}^{-1}\right)$ models using Sentinel-1B data. Concluding from the combined errors, the wind speeds of Sentinel-1B is thought to be slightly accurate by $0.12-0.21 \mathrm{~m} \cdot \mathrm{s}^{-1}$ for CMOD5.N and CMOD5.Na than those of Sentinel-1A. However, the three GMFs (CMOD4, CMOD_IFR2, and CMOD5) showed better accuracies with combined errors of Seninel-1A $\left(1.77,1.88,1.68 \mathrm{~m} \cdot \mathrm{s}^{-1}\right)$ than Sentinel-1B $\left(2.15,1.94,1.82 \mathrm{~m} \cdot \mathrm{s}^{-1}\right)$ as shown in Fig. 16(a).

ESA improved the performance of Sentinel-1A data through change in the calibration procedure on November 25, 2015 [85]. 
The earliest data acquisitions from Sentinel-1A (up until the date) have not been exposed to fine tuning of calibration [85], which might yield potential influences on the accuracy of wind speeds in this study. In order to investigate its impact on the accuracy of each GMF, we classified the matchup data into two groups before and after the calibration (Period 1: from May 1, 2015, to November 25, 2015, Period 2: from November 25, 2015, to September 30, 2017). As was indicated in Fig. 16(b), the RMSE of the estimated wind speeds tended to be reduced from the highest value of about $2.18 \mathrm{~m} \cdot \mathrm{s}^{-1}$ (CMOD5.N) to the lowest one of about $1.60 \mathrm{~m} \cdot \mathrm{s}^{-1}$ (CMOD5.Na). The combined errors $\left(E_{\mathrm{com}}\right)$ of these models were remarkably small of about 1.63 and $1.60 \mathrm{~m} \cdot \mathrm{s}^{-1}$ after the calibration date. This improvement was also found in the bias errors of about 0.22 and $0.04 \mathrm{~m} \cdot \mathrm{s}^{-1}$ for the two models.

However, the first three models revealed reverse trends with more amplified bias errors from positive biases $\left(0.19-0.55 \mathrm{~m} \cdot \mathrm{s}^{-1}\right)$ to significantly negative bias errors $(-0.74$ to $\left.-0.47 \mathrm{~m} \cdot \mathrm{s}^{-1}\right)$. For instance, the RMSE of the CMOD_IFR2 model decreased slightly by $0.07 \mathrm{~m} \cdot \mathrm{s}^{-1}$ after the calibration, but the bias changed to a negative value to $-0.66 \mathrm{~m} \cdot \mathrm{s}^{-1}$ [see Fig. 16(b)]. When the collocated data were sampled for the same matchup numbers $(N=75)$ before and after the calibration procedure, the combined errors, $E_{\text {com }}$, of all models became reduced by $12.2 \%$. With the performance of calibration procedure, CMOD_IFR2 wind speeds were improved by $7.9 \%$ from 1.89 to $1.74 \mathrm{~m} \cdot \mathrm{s}^{-1}$, CMOD5.Na wind speeds were more accurate by $21.8 \%$ from 2.34 to $1.83 \mathrm{~m} \cdot \mathrm{s}^{-1}$, and CMOD5.N by $20.3 \%$ from 2.51 to $2.00 \mathrm{~m} \cdot \mathrm{s}^{-1}$. This implies that the CMOD5.Na and CMOD5.N models were likely to respond more sensitively to the calibration procedure with improvements in the estimation of wind speed as shown in Fig. 16(b).

\section{Other Potential Cause of Wind Speed Error}

One of other error sources may be the high NRCS values because of random and irregular radar interference, particularly in the coastal regions. Fig. 17 shows extreme cases of radar interference in a Sentinel-1A/B NRCS image along the western coastal region of the Korean Peninsula in the Yellow Sea. The red stars in each image represent the KMA marine meteorological buoys in the Sentinel-1A/B images from the matchup database. Spatial patterns of the radar interference in the Sentinel-1A/B NRCS can be classified into several types including zonally elongated features as mostly shown in the green rectangles of Fig. 17, zonally elongated with stripe-like and irregular small boxes, and randomly distributed isolated box types. The locations of the KMA marine meteorological buoys did not coincide with the locations of the radar interference in the Sentinel-1A/B image. Thus, such radar interference did not seem to influence the validation results of the wind speeds in this study. Nonetheless, the abundant random signals of radar interference in the SAR images suggest that an automatic methodology for the removal of the radar interference should be developed so as to improve the accuracy of the wind speeds in the near real time.
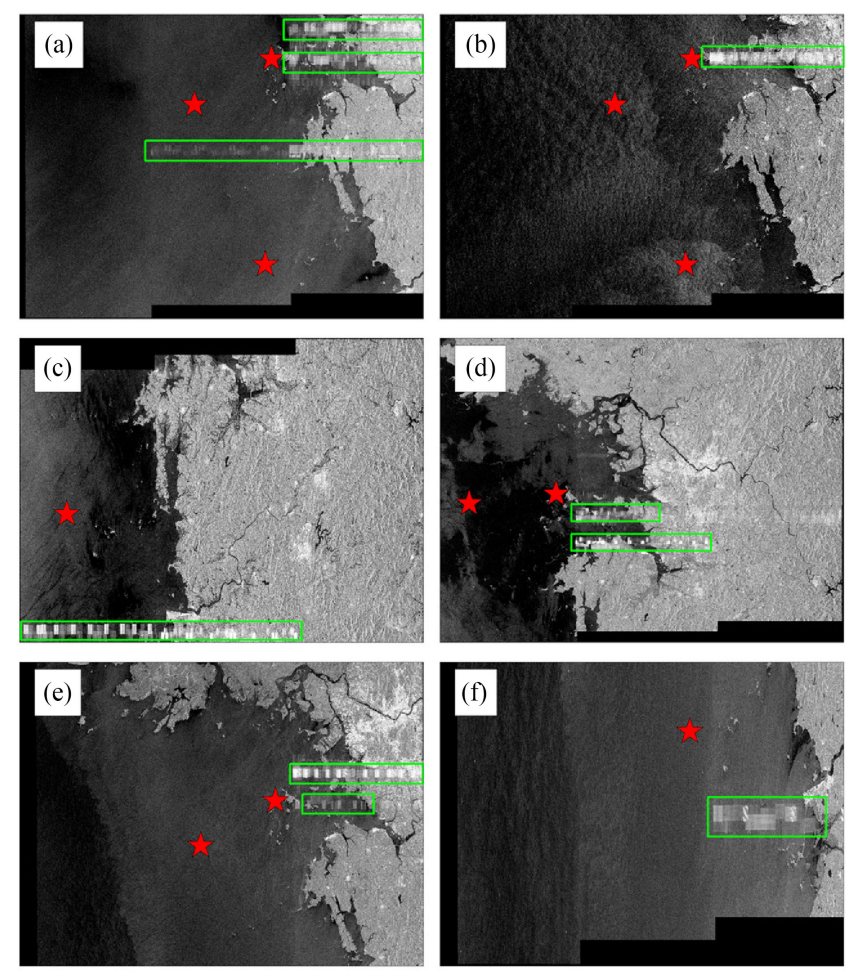

Fig. 17. NRCS of the Sentinel-1A/B images including the radar interference in the seas around the Korean Peninsula, on (a) December 13, 2015, (b) January 6, 2016, (c) May 24, 2016, (d) July 11, 2016, (e) January 18, 2017, and (f) January 18, 2017, where the red stars and green boxes indicate the KMA marine meteorological buoys and the radar interferences in the Sentinel-1A/B images, respectively.

\section{SUMMARY AND CONCLUSION}

For validation of sea surface wind speeds derived from the Sentinel-1A/B IW mode data using CMOD functions, a matchup database between the Sentinel-1A/B IW mode data and the KMA marine meteorological buoys was developed for the period from May 1, 2015, to September 20, 2017. In total, 395 NRCS images from Sentinel-1A/B IW mode VV-polarized data were collected and used to produce the matchup database of 807 collocation points within approximately $20 \mathrm{~m}$ and $1 \mathrm{~h}$. To verify the accuracy of the SAR wind speed based on each CMOD function, the CMOD4, CMOD_IFR2, CMOD5, CMOD5.N, and CMOD5.Na functions were used to estimate the wind speeds and their results were compared to in situ measurements from the KMA buoy stations. Because the heights of the in situ wind speed $(3.6-4.0 \mathrm{~m})$ were different from those of the SAR-derived wind speed $(10 \mathrm{~m})$, the LKB model was used to convert the in situ wind speed to a $10-\mathrm{m}$ neutral wind.

In the seas around the Korean Peninsula, the RMSEs of the CMOD4, CMOD_IFR2, CMOD5, CMOD5.N, and CMOD5.Na functions were approximately $1.83,1.82,1.69$, 1.68 , and $1.65 \mathrm{~m} \cdot \mathrm{s}^{-1}$, respectively. The RMSEs of all of the CMOD functions were less than $2 \mathrm{~m} \cdot \mathrm{s}^{-1}$, which satisfies the limit of the expected accuracy of sea surface wind speed from existing SAR instruments. Although there was no significant bias for each CMOD function, all of the CMOD functions except for CMOD_IFR2 tended to overestimate the wind speeds 
at low wind speeds of less than $5 \mathrm{~m} \cdot \mathrm{s}^{-1}$. The differences between Sentinel-1A/B winds and buoy winds presented distinctive characteristics depending on the regional characteristics of the coastal areas in the western, eastern, and southern regions off the Korean Peninsula such as water depth and bathymetry. The RMSEs of the wind speed based on the CMOD functions were approximately $1.66 \mathrm{~m} \cdot \mathrm{s}^{-1}$ (CMOD5.Na), $1.61 \mathrm{~m} \cdot \mathrm{s}^{-1}$ (CMOD5.Na), and $1.54 \mathrm{~m} \cdot \mathrm{s}^{-1}$ (CMOD5) in the EJS, the southern region, and the Yellow Sea, respectively. Overall, the biases of wind speed errors using all of the CMOD functions were higher in the Yellow Sea than in the eastern region or the southern region. The accuracies of the in situ wind speeds lower than $5 \mathrm{~m} \cdot \mathrm{s}^{-1}$ and higher than $10 \mathrm{~m} \cdot \mathrm{s}^{-1}$ of the CMOD functions showed the smallest RMSEs in the cases of the CMOD4 $\left(1.24 \mathrm{~m} \cdot \mathrm{s}^{-1}\right)$ and CMOD5.N $\left(1.89 \mathrm{~m} \cdot \mathrm{s}^{-1}\right)$ models, respectively. As the bathymetry decreases, the errors of the SAR wind speeds were amplified with overestimation by $1.01 \mathrm{~m} \cdot \mathrm{s}^{-1}(<40 \mathrm{~m})$ in the case of the CMOD5.Na model, dominantly appearing in the shallow region of the Yellow Sea.

The wind speed errors are associated with diverse factors in the coastal regions. The spatial distribution of the Sentinel$1 \mathrm{~A} / \mathrm{B}$ wind speeds showed potential causes of wind speed errors because of the regional and specific characteristics of the coastal region around the Korean Peninsula. The sand ridges over the shallow region influenced the sea surface roughness because of the interaction between the bathymetry and tidal current, which resulted in significantly overestimated wind speeds. The errors indicated dependence on wind direction differences as expected from the wind speed ratio from the CMOD model.

In addition, modified NRCS values, in relation to radar interference with an abnormal, irregular, and random distribution in the SAR images, also resulted in overestimation of wind speeds and underestimation in part. For the retrieval of accurate wind speeds from SAR data, it is necessary to consider the potential causes of errors beforehand and develop a processing technique to eliminate problematic portions of the SAR images.

According to the results of comparison of Sentinel-1A and Sentinel-1B and the effect of calibration improvement as of November 25, 2015, the accuracies of CMOD5.N and CMOD5.Na functions tended to be increased. These results imply that the change in calibration procedure of the SAR data would affect the wind speed errors as well. Thus, this study showed that more robust calibration procedure should be substantially established before diverse applications of the SAR data can be activated.

Many studies have long been conducted of the validation of sea surface wind speed from SAR data to investigate the accuracies and errors induced by different SAR sensors, preprocessing methods, wind direction retrieval methods, GMFs, polarization ratios, and so on. Most of these studies have showed not only successful accuracy but also regional dependence because of local atmospheric, oceanic, geologic, and biogenic conditions or other pollution-related matters. Unless deliberate consideration of the regional characteristics is given during the wind retrieval procedure, inaccurate wind fields may be produced and utilized for diverse purposes. Such errors can be potentially reduced through an in-depth understanding of regional characteristics such as in the seas around the Korean Peninsula. The charac- teristics of the sea surface wind errors with diverse topographic and other conditions in this study are expected to contribute to the understanding of the general characteristics of SAR wind errors and the development of improved wind speed retrieval algorithms to reduce errors by considering regionally specific environments.

Thus, to improve the accuracy of SAR-derived wind speeds, intensive and more frequent observations of Sentinel-1A/B are needed in coastal regions with diverse sources of potential errors in relation to the atmospheric and oceanic environments. In addition, coastal regions should have many atmospheric and oceanic buoy stations with accurate in situ measurements. Only after the construction of an extensive and accurate matchup database and application of a scheme to remove or reduce errors can SAR wind field data be utilized for operational purposes. Otherwise, the accuracy and quality of operational local wind products may be degraded and the availability of accurate SARderived wind fields may be insufficient. Given this, this study addresses the importance of continuous validation and an understanding of regional characteristics of SAR-derived wind fields for more extensive and operational use of worldwide Sentinel1A/B-derived wind fields.

Since all empirical GMFs have been globally developed, mostly based on scatterometer cells with much larger than SAR, the present validation at local coastal regions might not take into account peculiar effects due to diverse factors such as fetchlimited coastal situations, shallow-water environmental conditions, sea states, surface currents, or sea surface temperature [86]-[91]. Moreover, the performance of different GMFs found through this analysis is not necessarily representative for other SAR sensors or for other areas of the world. The different procedure of sensor calibrations or atmospheric conditions with strong locality, such as dominant wind patterns, atmospheric stratification, or local climate, may also have major impacts on the bias. One of approaches to overcome such unsolved issues may be the possible combined use of dual- and quad-pol measurements because the VV-HH can isolate the short-scale roughness remarkably, very closely related to wind forcing as relaxation time is small for the short scales. By contrast, VV or $\mathrm{HH}$ alone also carry tilting effects that will vary with environmental conditions such as fetch, bathymetry, or current [92], [93]. The other approach can be acquired from the possibility to use the cross-pol VH, known to have a much weaker wind directional modulation, to help infer a first-guess sea state information, and to help retrieve the short-scale information from VV measurements [94]. Thus, further investigations should be promoted to make combined polarized measurements, possibly augmented with Doppler information when available, to improve local wind estimates from SAR measurements in the future.

\section{REFERENCES}

[1] J. E. Graf, W.-Y. Tsi, and L. Jones, "Overview of QuikSCAT missionA quick deployment of a high resolution, wide swath scanning scatterometer for ocean wind measurement," in Proc. IEEE Southeastcon Eng. New Era, Orlando, FL, USA, 1998, pp. 314-317, doi: 10.1109/SECON.1998.673359.

[2] K. Liu and J. C. Chan, "Size of tropical cyclones as inferred from ERS-1 and ERS-2 data," Monthly Weather Rev., vol. 127, no. 12, pp. 2992-3001, Dec. 1999, doi: 10.1175/1520-0493(1999)127<2992:SOTCAI>2.0.CO;2. 
[3] N. Ebuchi, "Statistical distribution of wind speeds and directions globally observed by NSCAT," J. Geophys. Res., vol. 104, no. C5, pp. 11393-11403, May 1999, doi: 10.1029/98JC02061.

[4] C. M. Risien and D. B. Chelton, "A global climatology of surface wind and wind stress fields from eight years of QuikSCAT scatterometer data," J. Phys. Oceanogr., vol. 38, no. 11, pp. 2379-2413, Nov. 2008, doi: 10.1175/2008JPO3881.1

[5] W. T. Liu, W. Tang, and P. S. Polito, "NASA scatterometer provides global ocean-surface wind fields with more structures than numerical weather prediction," Geophys. Res. Lett., vol. 25, no. 6, pp. 761-764, Mar. 1998, doi: 10.1029/98GL00544.

[6] Y. Quilfen, B. Chapron, T. Elfouhaily, K. Katsaros, and J. Tournadre, "Observation of tropical cyclones by high-resolution scatterometry," J. Geophys. Res., vol. 103, no. C4, pp. 7767-7786, 1998.

[7] K.-A. Park and P. C. Cornillon, "Stability-induced modification of sea surface winds over Gulf Stream rings," Geophys. Res. Lett., vol. 29, no. 24, pp. 64-1-64-4, Dec. 2002, doi: 10.1029/2001GL014236.

[8] D. B. Chelton et al., "Observations of coupling between surface wind stress and sea surface temperature in the eastern tropical $\mathrm{Pa}$ cific," J. Clim., vol. 14, no. 7, pp. 1479-1498, Apr. 2001, doi: 10.1175/1520-0442(2001)014<1479: OOCBSW>2.0.CO;2.

[9] D. B. Chelton, M. G. Schlax, M. H. Freilich, and R. F. Milliff, "Satellite measurements reveal persistent small-scale features in ocean winds," Science, vol. 303, no. 5660, pp. 978-983, 2004.

[10] L. W. O'neill, D. B. Chelton, S. K. Esbensen, and F. J. Wentz, "Highresolution satellite measurements of the atmospheric boundary layer response to SST variations along the Agulhas Return Current," J. Clim., vol. 18, no. 14, pp. 2706-2723, Jul. 2005, doi: 10.1175/JCLI3415.1.

[11] K.-A. Park, P. Cornillon, and D. L. Codiga, "Modification of surface winds near ocean fronts: Effects of Gulf Stream rings on scatterometer (QuikSCAT, NSCAT) wind observations," J. Geophys. Res., vol. 111, no. C03021, pp. 1-19, 2006, doi: 10.1029/2005JC003016.

[12] D. R. Thompson and R. C. Beal, "Mapping mesoscale and submesoscale wind fields using synthetic aperture radar," in Proc. IEEE Int. Geosci. Remote Sens. Sens. Manag. Environ., Seattle, WA, USA, vol. 3, 1998, pp. 1382-1384, doi: 10.1109/IGARSS.1998.691431.

[13] X. Yang, X. Li, W. G. Pichel, and Z. Li, "Comparison of ocean surface winds from ENVISAT ASAR, MetOp ASCAT scatterometer, buoy measurements, and NOGAPS model," IEEE Trans. Geosci. Remote Sens., vol. 49, no. 12, pp. 4743-4750, Dec. 2011, doi: 10.1109/TGRS.2011.2159802.

[14] E. Korsbakken, J. A. Johannessen, and O. M. Johannessen, "Coastal wind field retrievals from ERS synthetic aperture radar images," J. Geophys. Res., vol. 103, no. C4, pp. 7857-7874, 1998.

[15] B. R. Furevik and E. Korsbakken, "Comparison of derived wind speed from synthetic aperture radar and scatterometer during the ERS tandem phase," IEEE Trans. Geosci. Remote Sens., vol. 38, no. 2, pp. 1113-1121, Mar. 2000, doi: 10.1109/36.841990.

[16] X. Yang, X. Li, Q. Zheng, X. Gu, W. G. Pichel, and Z. Li, "Comparison of ocean-surface winds retrieved from QuikSCAT scatterometer and Radarsat-1 SAR in offshore waters of the US west coast," IEEE Geosci. Remote Sens. Lett., vol. 8, no. 1, pp. 163-167, Jan. 2011, doi: 10.1109/LGRS.2010.2053345.

[17] G. Marmorino, R. Jansen, G. Valenzuela, C. Trump, J. Lee, and J. Kaiser, "Gulf Stream surface convergence imaged by synthetic aperture radar," J. Geophys. Res., vol. 99, no. C9, pp. 18315-18328, 1994, doi: 10.1029/94JC01643.

[18] J. A. Johannessen et al., "Coastal ocean fronts and eddies imaged with ERS 1 synthetic aperture radar," J. Geophys. Res., vol. 101, no. C3, pp. 6651-6667, Mar. 1996, doi: 10.1029/95JC02962.

[19] X. Li, W. Zheng, W. G. Pichel, C. Z. Zou, and P. Clemente-Colón, "Coastal katabatic winds imaged by SAR," Geophys. Res. Lett., vol. 34, no. L03804, pp. 1-5, 2007, doi: 10.1029/2006GL028055.

[20] X. Li, X. Li, and M. He, "Coastal upwelling observed by multi-satellite sensors," Sci. China Ser. D, Earth Sci., vol. 52, no. 7, pp. 1030-1038, Jul. 2009, doi: 10.1007/s11430-009-0088-x.

[21] X. Li et al., "Tropical cyclone morphology from spaceborne synthetic aperture radar," Bull. Amer. Meteorol. Soc., vol. 94, no. 2, pp. 215-230, Feb. 2013, doi: 10.1175/BAMS-D-11-00211.1.

[22] X. Li et al., "Observation of hurricane-generated ocean swell refraction at the Gulf Stream north wall with the RADARSAT-1 synthetic aperture radar," IEEE Trans. Geosci. Remote Sens., vol. 40, no. 10, pp. 2131-2142, Oct. 2002.

[23] X. Li, C. Dong, P. Clemente-Colón, W. G. Pichel, and K. S. Friedman, "Synthetic aperture radar observation of the sea surface imprints of upstream atmospheric solitons generated by flow impeded by an island,"
J. Geophys. Res., vol. 109, no. C02016, pp. 1-8, 2004, doi: 10.1029/2003JC002168

[24] X. Li, W. Zheng, X. Yang, Z. Li, and W. G. Pichel, "Sea surface imprints of coastal mountain lee waves imaged by synthetic aperture radar," J. Geophys. Res., vol. 116, no. C02014, pp. 1-10, 2011, doi: 10.1029/2010JC006643

[25] T.-S. Kim, K.-A. Park, X. Li, and S. Hong, "SAR-derived wind fields at the coastal region in the East/Japan Sea and relation to coastal upwelling," Int. J. Remote Sens., vol. 35, nos. 11/12, pp. 3947-3965, 2014.

[26] T.-S. Kim, K.-A. Park, X. Li, A. A. Mouche, B. Chapron, and M. Lee, "Observation of wind direction change on the sea surface temperature front using high-resolution full polarimetric SAR data," IEEE J. Sel. Topics Appl. Earth Observ. Remote Sens., vol. 10, no. 6, pp. 2599-2607, Jun. 2017, doi: 10.1109/JSTARS.2017.2660858.

[27] A. Stoffelen and D. Anderson, "Scatterometer data interpretation: Estimation and validation of the transfer function CMOD4," J. Geophys. Res., vol. 102, no. C3, pp. 5767-5780, Mar. 1997, doi: 10.1029/96JC02860.

[28] IFREMER-CERSAT, "Off-line wind scatterometer ERS products: User manual: Version 2.0," IFREMER-CERSAT, Plouzane, France, Tech. Rep. C2-MUT-W-O1-IF, 1999.

[29] H. Hersbach, A. Stoffelen, and S. De Haan, "The improved C-band geophysical model function CMOD5," in Proc. Envisat ERS Symp., 2005, vol. 572, pp. 142.1-142.8

[30] H. Hersbach, A. Stoffelen, and S. de Haan, "An improved C-band scatterometer ocean geophysical model function: CMOD5," J. Geophys. Res., vol. 112, no. C03006, pp. 1-18, 2007, doi: 10.1029/2006JC003743.

[31] H. Hersbach, "Comparison of C-band scatterometer CMOD5.N equivalent neutral winds with ECMWF," J. Atmos. Ocean. Technol., vol. 27, no. 4, pp. 721-736, Apr. 2010, doi: 10.1175/2009JTECHO698.1.

[32] J. Verspeek, A. Stoffelen, A. Verhoef, and M. Portabella, "Improved ASCAT wind retrieval using NWP ocean calibration," IEEE Trans. Geosci. Remote Sens., vol. 50, no. 7, pp. 2488-2494, Jul. 2012, doi: 10.1109/TGRS.2011.2180730.

[33] F. Fetterer, D. Gineris, and C. C. Wackerman, "Validating a scatterometer wind algorithm for ERS-1 SAR," IEEE Trans. Geosci. Remote Sens., vol. 36, no. 2, pp. 479-492, Mar. 1998.

[34] F. M. Monaldo, D. R. Thompson, R. C. Beal, W. G. Pichel, and P. Clemente-Colon, "Comparison of SAR-derived wind speed with model predictions and ocean buoy measurements," IEEE Trans. Geosci. Remote Sens., vol. 39, no. 12, pp. 2587-2600, Dec. 2001.

[35] M. Bruun Christiansen, W. Koch, J. Horstmann, C. Bay Hasager and M. Nielsen, "Wind resource assessment from C-band SAR," Remote Sens. Environ., vol. 105, no. 1, pp. 68-81, Nov. 2006, doi: 10.1016/j.rse.2006.06.005.

[36] T.-S. Kim, K.-A. Park, and W.-I. Moon, "Wind vector retrieval from SIRC SAR data off the east coast of Korea," J. Korean Earth Sci. Soc., vol. 31, no. 5, pp. 475-487, Sep. 2010, doi: 10.5467/JKESS.2010.31.5.475.

[37] W. M. Moon, G. Staples, D. Kim, S. Park, and K.-A. Park, "RADARSAT2 and coastal applications: Surface wind, waterline, and intertidal flat roughness," Proc. IEEE, vol. 98, no. 5, pp. 800-815, May 2010, doi: 10.1109/JPROC.2010.2043331.

[38] E. Attema et al., "Sentinel-1-the radar mission for GMES operational land and sea services," ESA Bull., vol. 131, pp. 10-17, 2007.

[39] F. De Zan and A. M. Guarnieri, "TOPSAR: Terrain observation by progressive scans," IEEE Trans. Geosci. Remote Sens., vol. 44, no. 9, pp. 2352-2360, Sep. 2006, doi: 10.1109/TGRS.2006.873853.

[40] R. Torres et al., "GMES Sentinel-1 mission," Remote Sens. Environ., vol. 120, pp. 9-24, May 2012, doi: 10.1016/j.rse.2011.05.028.

[41] F. Monaldo, C. Jackson, X. Li, and W. G. Pichel, "Preliminary evaluation of sentinel-1A wind speed retrievals," IEEE J. Sel. Topics Appl. Earth Observ. Remote Sens., vol. 9, no. 6, pp. 2638-2642, Jun. 2016, doi: 10.1109/JSTARS.2015.2504324.

[42] KMA, Guidelines for Comprehensive Data Quality Management. Seoul, South Korea: KMA, Jun. 2016 (in Korean).

[43] S. Lehner, J. Horstmann, W. Koch, and W. Rosenthal, "Mesoscale wind measurements using recalibrated ERS SAR images," J. Geophys. Res., vol. 103, no. C4, pp. 7847-7856, Apr. 1998, doi: 10.1029/97JC02726.

[44] P. W. Vachon and F. W. Dobson, "Wind retrieval from RADARSAT SAR images: Selection of a suitable C-band $\mathrm{HH}$ polarization wind retrieval model," Can. J. Remote Sens., vol. 26, no. 4, pp. 306-313, Aug. 2000.

[45] W. Koch, "Directional analysis of SAR images aiming at wind direction," IEEE Trans. Geosci. Remote Sens., vol. 42, no. 4, pp. 702-710, Apr. 2004, doi: 10.1109/TGRS.2003.818811.

[46] B. Zhang et al., "Ocean vector winds retrieval from C-band fully polarimetric SAR measurements," IEEE Trans. Geosci. Remote Sens., vol. 50, no. 11, pp. 4252-4261, Nov. 2012, doi: 10.1109/TGRS.2012.2194157. 
[47] B. Zhang, X. Li, W. Perrie, and Y. He, "Synergistic measurements of ocean winds and waves from SAR," J. Geophys. Res., vol. 120, no. 9, pp. 6164-6184, Sep. 2015, doi: 10.1002/2015JC011052.

[48] B. Rabus, M. Eineder, A. Roth, and R. Bamler, "The shuttle radar topography mission-A new class of digital elevation models acquired by spaceborne radar," ISPRS J. Photogramm. Remote Sens., vol. 57, no. 4, pp. 241-262, Feb. 2003.

[49] T. G. Farr et al., "The shuttle radar topography mission," Rev. Geophys., vol. 45, no. 2, pp. 1-33, May 2007, doi: 10.1029/2005RG000183.

[50] A. H. S. Solberg, G. Storvik, R. Solberg, and E. Volden, "Automatic detection of oil spills in ERS SAR images," IEEE Trans. Geosci. Remote Sens., vol. 37, no. 4, pp. 1916-1924, Jul. 1999.

[51] P. Vachon, S. Thomas, J. Cranton, C. Bjerkelund, F. Dobson, and R. Olsen, "Monitoring the coastal zone with the RADARSAT satellite," in Proc. Oceanol. Int., vol. 98, pp. 10-13, Mar. 1998.

[52] K. Eldhuset, "An automatic ship and ship wake detection system for spaceborne SAR images in coastal regions," IEEE Trans. Geosci. Remote Sens., vol. 34, no. 4, pp. 1010-1019, Jul. 1996.

[53] D. J. Crisp, "The state-of-the-art in ship detection in synthetic aperture radar imagery," Intell. Surveillance Reconnaissance Div. Inf. Sci. Lab. Def. Sci. Technol. Org., May 2004.

[54] J.-S. Lee, "Speckle suppression and analysis for synthetic aperture radar images," Opt. Eng., vol. 25, May 1986, Art. no. 255636.

[55] G. A. Mastin, "Adaptive filters for digital image noise smoothing: An evaluation," Comp. Vis. Graph. Image Process., vol. 31, no. 1, pp. 103-121, 1985.

[56] D. M. Smith, "Speckle reduction and segmentation of synthetic aperture radar images," Int. J. Remote Sens., vol. 17, no. 11, pp. 2043-2057, Jul. 1, 1996, doi: 10.1080/01431169608948758.

[57] J. Horstmann, S. Lehner, and H. Schiller, "Global wind speed retrieval from complex SAR data using scatterometer models and neural networks," in Proc. 2001 IEEE Int. Geosci. Remote Sens. Symp. Scanning Present Resolving Future, Sydney, NSW, Australia, vol. 3, 2001, pp. 1553-1555, doi: 10.1109/IGARSS.2001.976908.

[58] K.-F. Dagestad et al., "Wind retrieval from synthetic aperture radar-An overview," in Proc. 4th SAR Oceanogr. Workshop Adv. SAR Oceanogr., Troms $\varnothing$, Norway, 2013, pp. 18-22.

[59] K. Zhang, X. Xu, B. Han, L. R. Mansaray, Q. Guo, and J. Huang, "The influence of different spatial resolutions on the retrieval accuracy of sea surface wind speed with $\mathrm{C}-2 \mathrm{PO}$ models using full polarization C-band SAR," IEEE Trans. Geosci. Remote Sens., vol. 55, no. 9, pp. 5015-5025, Sep. 2017, doi: 10.1109/TGRS.2017.2700942.

[60] W. T. Liu, K. B. Katsaros, and J. A. Businger, "Bulk parameterization of air-sea exchanges of heat and water vapor including the molecular constraints at the interface," J. Atmos. Sci., vol. 36, no. 9, pp. 1722-1735, Sep. 1979, doi: 10.1175/1520-0469(1979)036<1722:BPOASE >2.0.CO;2.

[61] W. T. Liu and W. Tang, "Equivalent neutral wind," JPL Publication 96-17, 1996, p. 8.

[62] C. A. Paulson, "The mathematical representation of wind speed and temperature profiles in the unstable atmospheric surface layer," J. Appl. Meteorol., vol. 9, no. 6, pp. 857-861, Dec. 1970, doi: 10.1175/1520-0450(1970)009<0857:TMROWS >2.0.CO;2.

[63] J. A. Businger, J. C. Wyngaard, Y. Izumi, and E. F. Bradley, "Flux-profile relationships in the atmospheric surface layer," J. Atmos. Sci., vol. 28, no. 2, pp. 181-189, Mar. 1971, doi: 10.1175/1520-0469(1971)028<0181:FPRITA >2.0.CO;2.

[64] A. Dyer, "A review of flux-profile relationships, "Boundary Layer Meteorol., vol. 7, no. 3, pp. 363-372, Nov. 1974, doi: 10.1007/BF00240838.

[65] A. A. Mouche, B. Chapron, B. Zhang, and R. Husson, "Combined coand cross-polarized SAR measurements under extreme wind conditions," IEEE Trans. Geosci. Remote Sens., vol. 55, no. 12, pp. 6746-6755, Dec. 2017, doi: 10.1109/TGRS.2017.2732508.

[66] Y. Takeyama, T. Ohsawa, K. Kozai, C. B. Hasager, and M. Badger, "Comparison of geophysical model functions for SAR wind speed retrieval in Japanese coastal waters," Remote Sens., vol. 5, no. 4, pp. 1956-1973, 2013.

[67] Y. Quilfen, B. Chapron, F. Collard, and D. Vandemark, "Relationship between ERS scatterometer measurement and integrated wind and wave parameters," J. Atmos. Ocean. Technol., vol. 21, no. 2, pp. 368-373, 2004.

[68] H. Hersbach, "CMOD5.N: A C-band geophysical model function for equivalent neutral wind," Eur. Centre Medium-Range Weather Forecast, Apr. 2008.

[69] B. Zhang and W. Perrie, "Cross-polarized synthetic aperture radar: A new potential measurement technique for hurricanes," Bull. Amer. Me- terol. Soc., vol. 93, no. 4, pp. 531-541, Apr. 2012, doi: 10.1175/BAMS-D-11-00001.1.

[70] J. Tournadre and Y. Quilfen, "Impact of rain cell on scatterometer data: 1. Theory and modeling," J. Geophys. Res., vol. 108, no. C7, pp. 18-1-18-14, Jul. 2003.

[71] J. Horstmann, H. Schiller, J. Schulz-Stellenfleth, and S. Lehner, "Global wind speed retrieval from SAR," IEEE Trans. Geosci. Remote Sens., vol. 41, no. 10, pp. 2277-2286, Oct. 2003.

[72] W. J. Donnelly et al., "Revised ocean backscatter models at $\mathrm{C}$ and $\mathrm{Ku}$ band under high-wind conditions," J. Geophys. Res., vol. 104, no. C5, pp. 11485-11497, 1999.

[73] Y. He, W. Perrie, Q. Zou, and P. W. Vachon, "A new wind vector algorithm for C-band SAR," IEEE Trans. Geosci. Remote Sens., vol. 43, no. 7, pp. 1453-1458, Jul. 2005.

[74] G. De Loor and H. B. Van Hulten, "Microwave measurements over the North Sea," Boundary Layer Meteorol., vol. 13, nos. 1-4, pp. 119-131, Jan. 1978, doi: 10.1007/BF00913866.

[75] G. De Loor, "The observation of tidal patterns, currents, and bathymetry with SLAR imagery of the sea," IEEE J. Ocean. Eng., vol. OE-6, no. 4, pp. 124-129, Oct. 1981, doi: 10.1109/JOE.1981.1145501.

[76] W. Alpers and I. Hennings, "A theory of the imaging mechanism of underwater bottom topography by real and synthetic aperture radar," J. Geophys. Res., vol. 89, no. C6, pp. 10529-10546, 1984.

[77] J. Vogelzang, G. Wensink, G. De Loor, H. Peters, and H. Pouwels, "Sea bottom topography with X-band SLAR: The relation between radar imagery and bathymetry," Int. J. Remote Sens., vol. 13, no. 10, pp. 1943-1958, Jul. 1992, doi: 10.1080/01431169208904242.

[78] R. Romeiser and W. Alpers, "An improved composite surface model for the radar backscattering cross section of the ocean surface: 2 . Model response to surface roughness variations and the radar imaging of underwater bottom topography," J. Geophys. Res., vol. 102, no. C11, pp. 25251-25267, Nov. 1997, doi: 10.1029/97JC00191.

[79] I. Hennings, "An historical overview of radar imagery of sea bottom topography," Int. J. Remote Sens., vol. 19, no. 7, pp. 1447-1454, Jan. 1998, doi: 10.1080/014311698215568.

[80] S. D. Smith et al., "Sea surface wind stress and drag coefficient: The HEXOS results," Boundary-Layer Meteor, vol. 60, nos. 1/2, pp. 109-142, Jul. 1992, doi: 10.1007/BF00122064.

[81] P. K. Taylor and M. J. Yelland, "The dependence of sea surface roughness on the height and steepness of the waves," J. Phys. Oceanogr., vol. 31, pp. 572-590, Feb. 2001, doi: 10.1175/1520-0485(2001)031<0572:TDOSSR >2.0.CO;2.

[82] P. Cornillon and K.-A. Park, "Warm core ring velocities inferred from NSCAT," Geophys. Res. Lett., vol. 28, no. 4, pp. 575-578, Feb. 2001, doi: 10.1029/2000GL011487.

[83] R. Pokhrel and H. Lee, "Estimation of the effective zone of sea/land breeze in a coastal area" Atmos. Pollut. Res., vol. 2, no. 1, pp. 106-115, 2011.

[84] T.-S. Kim, K.-A. Park, and M. Lee, "Modulation of tidal channel signatures on SAR images over Gyeonggi bay in relation to environmental factors," Remote Sens., vol. 10, no. 4, pp. 566-1-566-15, Apr. 2018, doi: $10.3390 / \mathrm{rs} 10040566$

[85] N. Miranda, S-1A TOPS Radiometric Calibration Refinement\#1. Paris, France: Eur. Space Agency, Nov. 24, 2015. [Online]. Available: https://sentinel.esa.int/documents/247904/2142675/Sentinel-1A_TOPS_ Radiometric_Calibration_Refinement

[86] D. Vandemark, J. B. Edson, and B. Chapron, "Altimeter estimation of sea surface wind stress for light to moderate winds," J. Atmos. Ocean. Technol., vol. 14, no. 3, pp. 716-722, 1997.

[87] Y. Quilfen, B. Chapron, and D. Vandemark, "The ERS scatterometer wind measurement accuracy: Evidence of seasonal and regional biases," J. Atmos. Ocean. Technol., vol. 18, no. 10, pp. 1684-1697, 2001.

[88] Y. Quilfen, B. Chapron, F. Collard, and D. Vandemark, "Relationship between ERS scatterometer measurement and integrated wind and wave parameters," J. Atmos. Ocean. Technol., vol. 21, no. 2, pp. 368-373, 2004.

[89] S. A. Grodsky, V. N. Kudryavtsev, A. Bentamy, J. A. Carton, and B. Chapron, "Does direct impact of SST on short wind waves matter for scatterometry?" Geophys. Res. Lett., vol. 39, no. L12602, pp. 1-6, 2012, doi: 10.1029/2012GL052091.

[90] A. M. Plagge, D. Vandemark, and B. Chapron, "Examining the impact of surface currents on satellite scatterometer and altimeter ocean winds," J. Atmos. Ocean. Technol., vol. 29, no. 12, pp. 1776-1793, 2012.

[91] H. Farjami, P. Golubkin, and B. Chapron, "Surveying sea surface effect in satellite altimeter-derived wind speed," Int. J. Coastal Offshore Eng., vol. -, no. 2, pp. 17-22, 2016. 
[92] V. N. Kudryavtsev, B. Chapron, A. G. Myasoedov, F. Collard, and J. A. Johannessen, "On dual co-polarized SAR measurements of the ocean surface," IEEE Geosci. Remote Sens. Lett., vol. 10, no. 4, pp. 761-765, Jul. 2013.

[93] V. Kudryavtsev, I. Kozlov, B. Chapron, and J. A. Johannessen, "Quadpolarization SAR features of ocean currents," J. Geophys. Res., vol. 119, no. 9, pp. 6046-6065, 2014.

[94] A. Mouche, and B. Chapron, "Global c-band envisat, RADARSAT-2 and Sentinel-1 SAR measurements in copolarization and cross-polarization," J. Geophys. Res., vol. 120, no. 11, pp. 7195-7207, 2015.

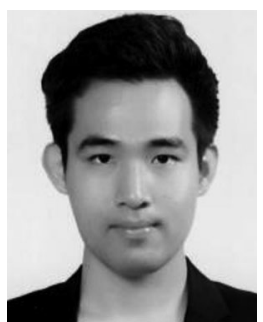

Jae-Cheol Jang received the B.S. degree in earth system science from Yonsei University, Seoul, South Korea, in 2015, and the M.S. degree in earth science education in 2018 from Seoul National University, Seoul, South Korea, where he is currently working toward the Ph.D. degree in earth science education.

His research interests include the study of oceanic phenomena in the coastal region using multisatellite data, oceanic application of polarimetric synthetic aperture radar (SAR) for target detection, and SAR oceanic application for oceanic parameter extractions.

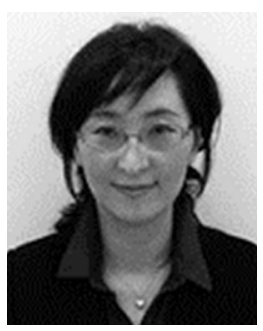

Kyung-Ae Park (M'11) received the B.S. degree in earth science education, the M.S. degree in physical oceanography, and the Ph.D. degree in satellite oceanography from Seoul National University, Seoul, South Korea, in 1987, 1989, and 1996, respectively.

Since 2007, she has been a Professor with the Department of Earth Science Education, Seoul National University. She has long utilized a variety of satellite remote-sensing techniques (sea surface temperature, near-surface wind, chlorophyll-a concentration, suspended sediment, wave height, sea level, and SAR) in her research and applied them for physical oceanographic applications including air-sea interaction and its linkage to climate change. Her research interests include the study of physical processes and ocean dynamics of mesoscale oceanic phenomena using multisatellite data and oceanic in situ measurements at regional scales in the East/Japan Sea and the marginal seas of the northwest Pacific Ocean.

Dr. Park was recipient of the Len Curtis Award of the International Journal of Remote Sensing, Remote Sensing and Photogrammetry Society's Annual Conference, U.K., in 2015.

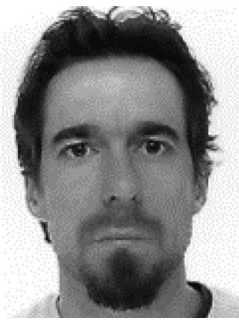

Alexis Aurélien Mouche received the Ph.D. degree in ocean remote sensing from CETP, IPSL, Centre Nationalde la Recherche Scientifique, Saint Maur, France, in 2005.

He joined the Laboratoire d'Océanographie Spatiale, IFREMER, Plouzané, France, in 2006, for a two-year Postdoctoral Fellow position granted by the French spatial agency (CNES) to work on ocean dynamics as observed at high resolution. From 2008 to 2013, he was a Research Engineer for BOOST and then CLS (CNES and IFREMER subsidiary) to develop algorithms for wind, waves, and current measurements with synthetic aperture radar (SAR) from space. Since January 2014, he has been with IFREMER, where he is currently a Research Scientist. He is currently involved in the CAL/VAL activities for European Sentinel-1A SAR, where he is in charge of the coordination of scientific activities to be conducted by expert support laboratories for ocean level-2 products. He is also involved in the preparation of the CAL/VAL activities for the Chinese French CFOSAT satellite and participates in the preparation of the IFREMER ocean waves products from level 2 to level 4. His research interests include the interactions of electromagnetic and oceanic waves for ocean remote-sensing applications.

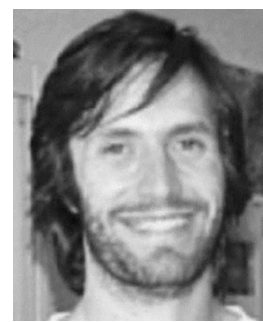

Bertrand Chapron was born in Paris, France, in 1962. He received the B.Eng. degree in physics from the Institut National Polytechnique de Grenoble, Grenoble, France, in 1984, and the Doctor at National Ph.D. degree in fluid mechanics from the University of Aix-Marseille II, Marseille, France, in 1988.

He spent three years as a Postdoctoral Research Associate with NASA/GSFC/Wallops Flight Facility, Wallops Island, VA, USA. He is currently responsible for the Oceanography from Space Laboratory, IFREMER, Plouzané, France. He has experience in applied mathematics, physical oceanography, electromagnetic waves theory, and its application to ocean remote sensing.

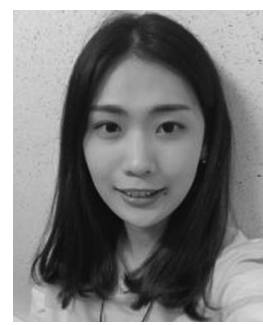

Ji-Hyun Lee received the B.S. and M.S. degrees in earth science education in 2017 and 2019, respectively, from Seoul National University, Seoul, South Korea, where she is currently working toward the $\mathrm{Ph} . \mathrm{D}$. degree in science education.

Her research interest includes the study of oceanic phenomena using synthetic aperture radar data, and sea ice detection and short term variations using highresolution satellite data around the Korean Peninsula. 